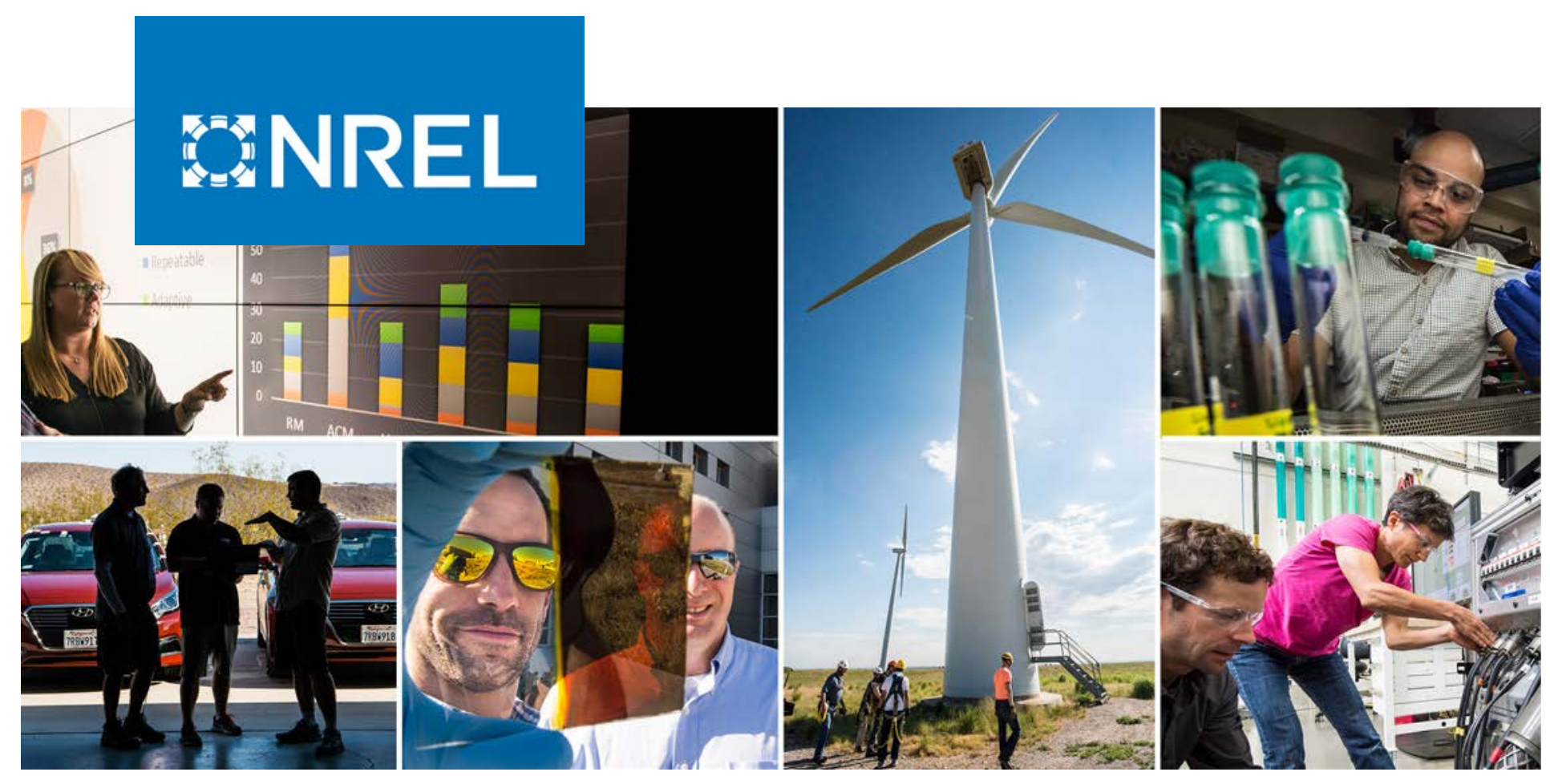

\title{
Puerto Rico Energy Efficiency Scenario Analysis Tool (PREESAT)
}

Monisha Shah, James Elsworth, Prateek Joshi, Ricardo

Castillo, and Kosol Kiatreungwattana

National Renewable Energy Laboratory

NREL is a national laboratory of the U.S. Department of Energy

Office of Energy Efficiency \& Renewable Energy

Operated by the Alliance for Sustainable Energy, LLC

This report is available at no cost from the National Renewable Energy Laboratory (NREL) at www.nrel.gov/publications.
Technical Report

NREL/TP-6A20-79977

September 2021 


\title{
GNREL
}

\section{Puerto Rico Energy Efficiency Scenario Analysis Tool (PREESAT)}

\author{
Monisha Shah, James Elsworth, Prateek Joshi, Ricardo \\ Castillo, and Kosol Kiatreungwattana
}

National Renewable Energy Laboratory

\section{Suggested Citation}

Shah, Monisha, James Elsworth, Prateek Joshi, Ricardo Castillo, and Kosol Kiatreungwattana. 2021. Puerto Rico Energy Efficiency Scenario Analysis Tool (PREESAT). Golden, CO: National Renewable Energy Laboratory. NREL/TP-6A2079977. https://www.nrel.gov/docs/fy21osti/79977.pdf.

NREL is a national laboratory of the U.S. Department of Energy Office of Energy Efficiency \& Renewable Energy Operated by the Alliance for Sustainable Energy, LLC

This report is available at no cost from the National Renewable Energy Laboratory (NREL) at www.nrel.gov/publications.

Contract No. DE-AC36-08GO28308
Technical Report

NREL/TP-6A20-79977

September 2021

National Renewable Energy Laboratory 15013 Denver West Parkway Golden, CO 80401 303-275-3000 • www.nrel.gov 


\section{NOTICE}

This work was authored by the National Renewable Energy Laboratory, operated by Alliance for Sustainable Energy, LLC, for the U.S. Department of Energy (DOE) under Contract No. DE-AC36-08GO28308. Funding provided by the U.S. Department of Energy Office of Energy Efficiency and Renewable Energy Building Technologies Office. The views expressed herein do not necessarily represent the views of the DOE or the U.S. Government.

This report is available at no cost from the National Renewable Energy Laboratory (NREL) at www.nrel.gov/publications.

U.S. Department of Energy (DOE) reports produced after 1991 and a growing number of pre-1991 documents are available free via www.OSTI.gov.

Cover Photos by Dennis Schroeder: (clockwise, left to right) NREL 51934, NREL 45897, NREL 42160, NREL 45891, NREL 48097, NREL 46526.

NREL prints on paper that contains recycled content. 


\section{Acknowledgments}

The authors would like to thank Elizabeth Arnold at the U.S. Department of Energy's Building Technology Office for her contributions and insights into this work.

We would also like to thank Joan Glickman and Adam Hasz at the Building Technologies Office for the insights, guidance, and support of this work.

We would like to thank Chioke Harris for modeling the commercial measures used in this analysis in NREL's SCOUT tool.

We would also like to thank all of those who reviewed this work and the spreadsheet tool, including Amaury Malive, Angel David Rodriguez, Augustín Irizarry, Carlos Tejera, Carlos Velazquez, Commisioner Ferdinand Ramos, Commissioner Lillian Mateo-Santos, Dmitri Cordero, Elaina Present, Emilio Colon-Zavala, Eric Wilson, Fernando Abruña, Fernando Agrait, Francisco Rullan, Gerardo Cosme, Gerardo Rodriguez, Jorge Hernandez, Jose Colucci,, Jose Maeso, Juan Lamboy, Meghan Mooney, PJ Wilson, Yan Carlo Oquendo. 


\section{List of Acronyms}

AC

BAU

DOE

ECM

GWh

HVAC

IRP

kWh

MW

NREL

PREB

PREESAT

PREPA

SEER

USVIEET air conditioning

Business as Usual

U.S. Department of Energy

energy conservation measure

gigawatt-hour

heating, ventilation, and air conditioning

integrated resource plan, Specifically PREPA's 2019 IRP

kilowatt-hour

megawatt

National Renewable Energy Laboratory

Puerto Rico Energy Bureau

Puerto Rico Energy Efficiency Scenario Analysis Tool

Puerto Rico Electric Power Authority

Seasonal Energy Efficiency Ratio

U.S. Virgin Islands Energy Efficiency Tool 


\section{Table of Contents}

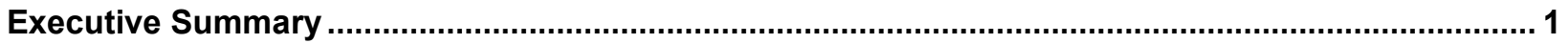

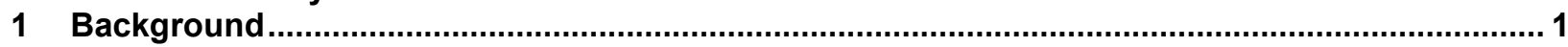

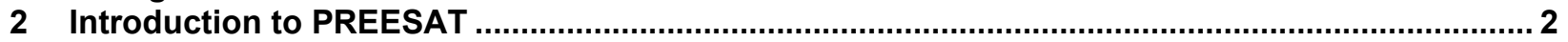

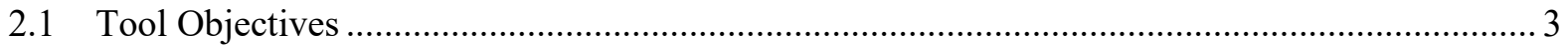

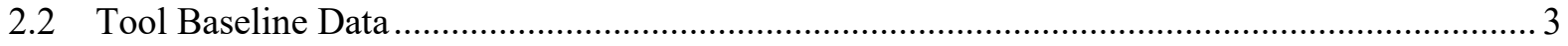

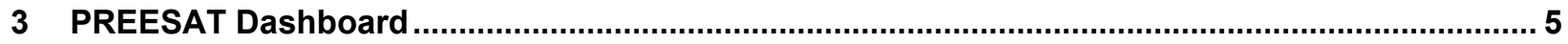

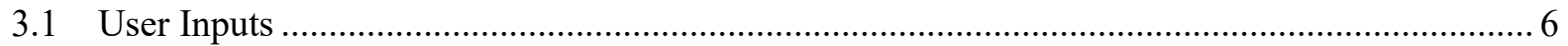

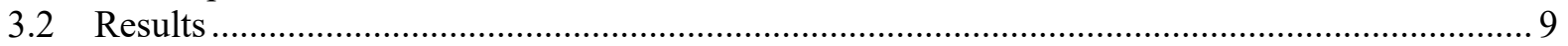

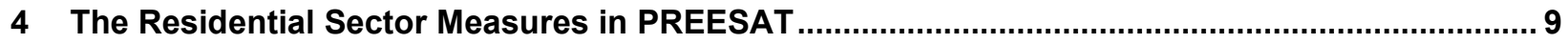

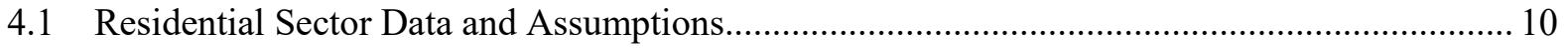

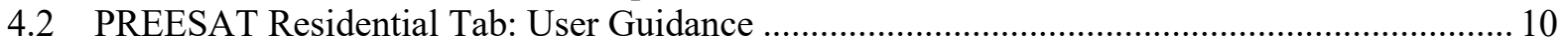

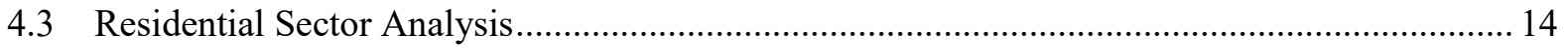

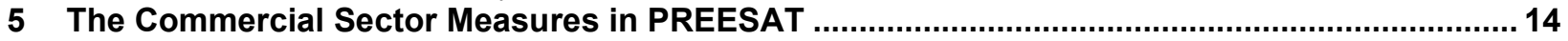

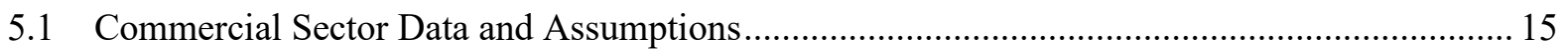

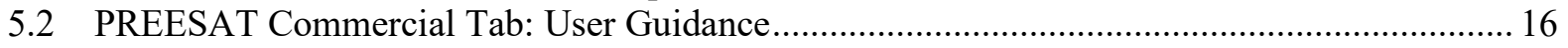

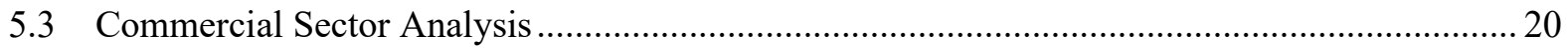

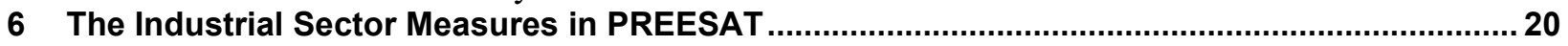

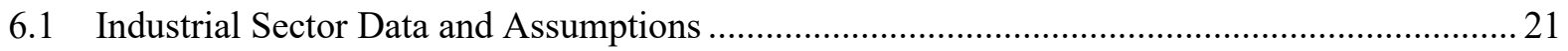

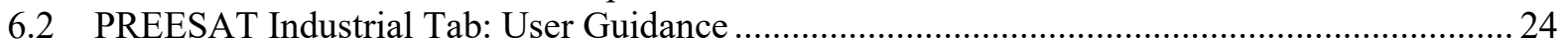

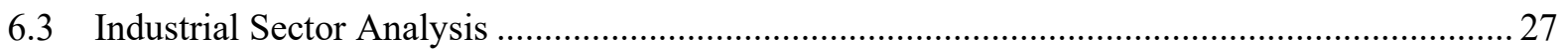

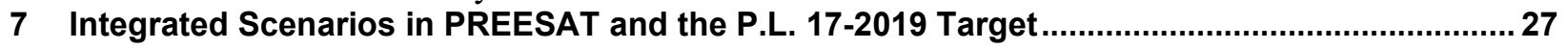

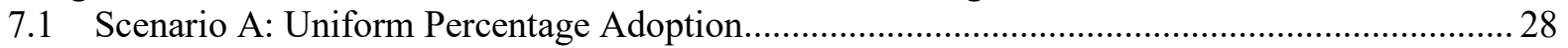

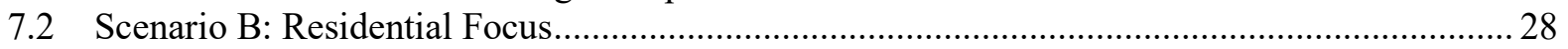

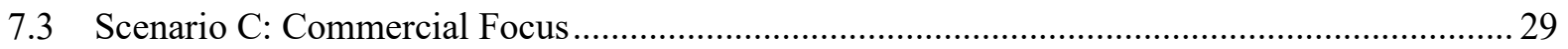

7.4 Scenario E: Cooling and Lighting Focus Across All Sectors............................................... 30

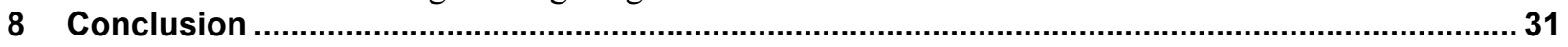

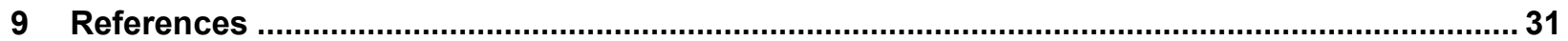




\section{List of Figures}

Figure 1. Historical Electricity Use in Puerto Rico.......................................................................... 2

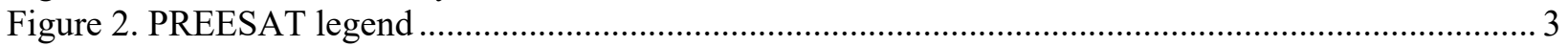

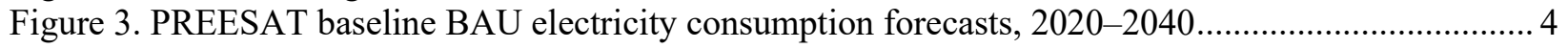

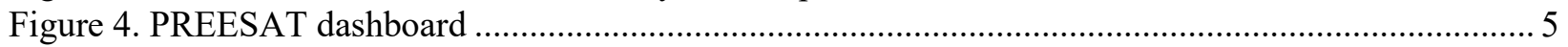

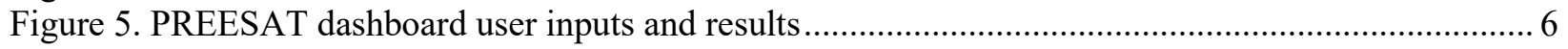

Figure 6. High Demand baseline BAU electricity consumption forecast by sector, 2020-2040................ 7

Figure 7. Electricity consumption forecasts for High Demand baseline BAU, hypothetical PREESAT

Analysis (NREL) EE scenario, and S-curve adoption profile for efficiency measures ........... 8

Figure 8 . Baseline BAU versus EE scenario electricity consumption breakdown by sector, $2040 \ldots \ldots \ldots \ldots . . .8$

Figure 9. PREESAT residential tab electricity consumption breakdown by end use ................................ 10

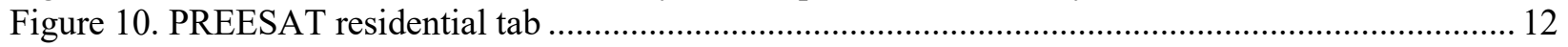

Figure 11. PREESAT residential tab efficiency measures for AC end use ............................................ 13

Figure 12. Calculation of electricity savings in 2040 (compared to the baseline) that are due to userspecified adoption levels for the Upgrade Window Unit from SEER 8.5 to SEER 12 measure

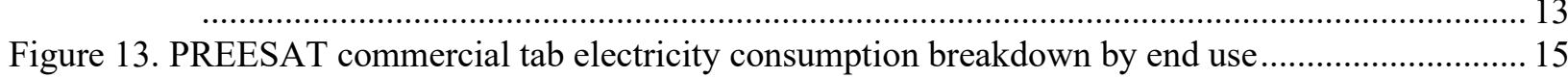

Figure 14. Calculation of relative electricity consumption of different commercial end use .................... 16

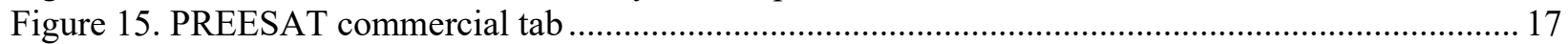

Figure 16. PREESAT commercial tab efficiency measures for HVAC end use .................................... 19

Figure 17. Calculation of electricity savings in 2040 (compared to the baseline) that due to user-specified adoption levels for the Best Commercial Rooftop AC measure ........................................... 19

Figure 18. Industrial sector electricity end uses in the mainland United States...................................... 21

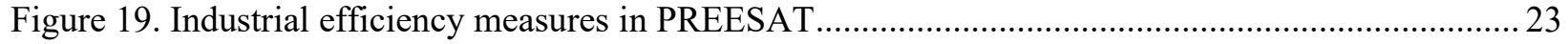

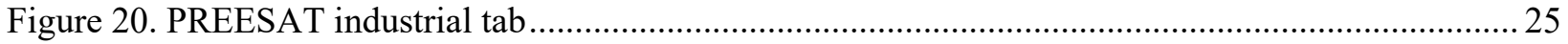

Figure 21. PREESAT industrial tab efficiency measures of Use Adjustable Frequency Drive or Multiple Speed Motors on Existing System .................................................................................... 26

Figure 22. Example calculation of electricity savings in 2040 (compared to the baseline) that are due to user-specified adoption levels for the Use Adjustable Frequency Drive or Multiple Speed

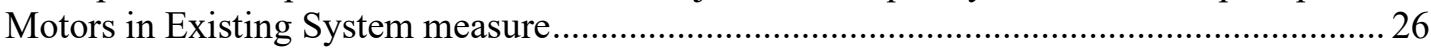

Figure 23. Total energy savings by 2040 as universal percentage adoption changes ............................. 28

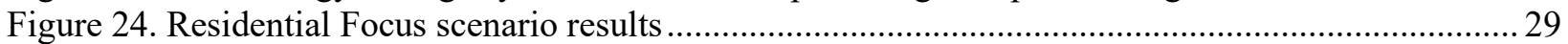

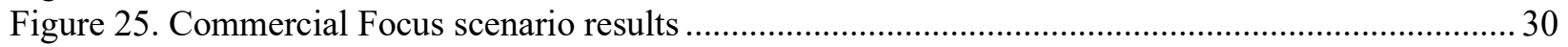

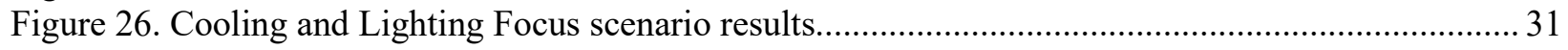




\section{Executive Summary}

Researchers at the U.S. Department of Energy's National Renewable Energy Laboratory (NREL) developed the Puerto Rico Energy Efficiency Scenario Analysis Tool (PREESAT) to inform decisions on energy efficiency programs in Puerto Rico, especially those formed to help attain the $30 \%$ energy reduction targets set out in P.L. 17-2019. PREESAT is a spreadsheet based customizable scenario tool, in which users can toggle input values and develop scenarios to reach certain levels of energy reductions from energy efficiency.

This report provides a background of the energy sector in Puerto Rico, an introduction to PREESAT, user guidance on how to use PREESAT (including separate guidance for the residential, commercial, and industrial input tabs), and sample scenarios illustrating example results.

\section{Background}

Puerto Rico's electricity system has traditionally relied on imported fossil fuels that power large, centralized generators. This reliance has led to high electricity prices, high air pollutant and greenhouse gas emissions, and fuel supply uncertainties. Additionally, these factors result in a less resilient power sector that has been exposed by recent disruptive events such as Hurricane Maria, the 2020 earthquakes, and bankruptcy proceedings for the Puerto Rico Electric Power Authority (PREPA) ${ }^{1}$.

Electricity demand in Puerto Rico has declined steadily over the past 15 years in conjunction with a decreasing population on the islands. According to PREPA's 2019 Integrated Resource Plan (IRP), annual electricity consumption declined from 20,163 gigawatt-hours (GWh) in 2003 to $16,375 \mathrm{GWh}$ in 2018. Peak demand declined from 3,546 megawatts (MW) in 2007 to 2,705 MW in 2018. Both consumption and demand have rebounded and have continued trends seen pre-Hurricane Maria (Figure 1). Of the total consumption in 2020, the residential sector's 1.3 million customers used 6,051 GWh (37\%), the commercial sector's 131,000 customers used 7,758 GWh (47\%), the industrial sector's 565 customers used 2,128 GWh (13\%), street lighting used $378 \mathrm{GWh}(2 \%)$, and agriculture and other uses accounted for $59 \mathrm{GWh}(0.4 \%)$. The residential sector has the most customers, the commercial sector uses the most total electricity, and the industrial sector uses the most electricity per customer; therefore, opportunities for targeted energy efficiency strategies exist for each sector.

\footnotetext{
${ }^{1}$ U.S. Energy Information Administration Puerto Rico Territory Profile. https://www.eia.gov/state/?sid=RQ
} 


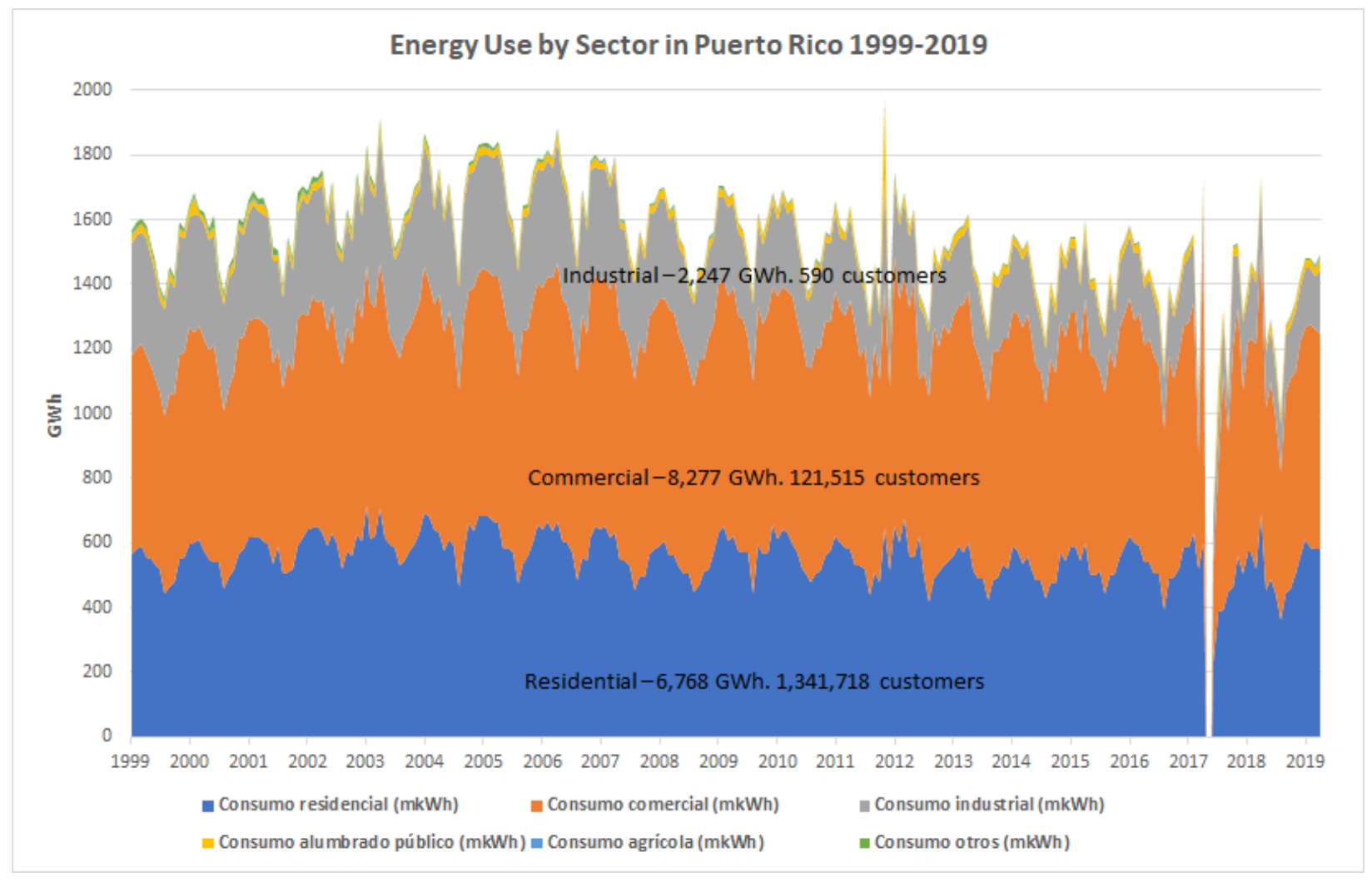

Figure 1. Historical Electricity Use in Puerto Rico

Source: Puerto Rico's integrated resource and resilience planning and U.S. Energy Information Administration

By reducing energy consumption, energy efficiency measures decrease stress on the power sector, increase resilience, and save customers money on their utility bills. Despite these benefits, Puerto Rico has not had a successful energy efficiency program because of a lack of legislated targets before 2019. However, P.L. 17-2019 established a mandate for a 30\% reduction in energy consumption via energy efficiency by 2040. To help achieve this mandated target, a utility bill rider of $\$ 0.001121 / \mathrm{kWh}$ (kilowatt-hour), which would have collected $\$ 13$ million/year for the first three years before increasing to $\$ 130$ million/year, was proposed to help fund this goal. Because of public backlash, the rider has not been implemented. In April 2021, the Puerto Rico Energy Bureau (PREB) released a draft Regulation for Energy Efficiency for public comment. This proposed regulation outlines the requirements for PREPA's energy efficiency programs to achieve the 30\% reduction still mandated in P.L. 17-2019. PREB also specified that the target set in P.L. 17-2019 is an annual cumulative reduction in electricity consumption of 4,744 GWh per year by 2040 , which is $30 \%$ of PREPA's FY19 sales.

\section{Introduction to PREESAT}

The National Renewable Energy Laboratory (NREL) developed the Puerto Rico Energy Efficiency Scenario Analysis Tool (PREESAT) to allow stakeholders to estimate the long-term aggregate electricity consumption impacts of various energy efficiency measures in Puerto Rico's residential, commercial, and industrial sectors. With PREESAT, the forecasted electricity savings for each sector are calculated using four main variables: (1) primary end-use loads, (2) 
appropriate efficiency measures for each end use, (3) estimated electricity savings for each efficiency measure, and (4) user-specified adoption levels by 2040 for each efficiency measure.

PREESAT is an energy accounting framework that addresses electricity use only; it does not consider specific programs or policies that might catalyze the user-entered adoption levels, the upfront cost of each energy efficiency measure, or optimization for the most cost-effective portfolio. The primary end-use loads (Variable 1) and the appropriate efficiency measures for each end use (Variable 2) are informed by extensive interviews with experts on the power sector in Puerto Rico. These interviews, conducted for the design of PREESAT, provided context on local construction practices, main end uses, and efficiency opportunities that have demonstrated to be cost-effective in prior studies and real-world settings. Furthermore, although the tool does not model thermal energy flows or building physics, the estimated electricity savings for each efficiency measure (Variable 3) are informed by available data sets and prior analysis based on full-scale building energy modeling.

\subsection{Tool Objectives}

PREESAT helps decision makers explore feasible future pathways to reduce territory-wide electricity consumption and reach energy efficiency targets, namely the P.L. 17-2019 target of a $30 \%$ reduction in energy use via energy efficiency by 2040 . Given the uncertainty about future changes in energy efficiency policies and technologies, it is important for decision makers to have a tool that can remain both policy and technology agnostic. Thus, PREESAT contains several customizable user inputs, and many of the default assumptions can be manually changed. The spreadsheet-based tool indicates which cells are intended to be user inputs, while other cells are either links, calculations, or hard entries (Figure 2).

\begin{tabular}{|c|l|l|l|l|}
\hline Legend: & $\begin{array}{l}\text { Calculated in } \\
\text { Spreadsheet }\end{array}$ & User Input & $\begin{array}{c}\text { Links to Other } \\
\text { Spreadsheet Data }\end{array}$ & Hard Entries \\
\hline
\end{tabular}

Figure 2. PREESAT legend

PREESAT can help stakeholders answer a variety of questions, including:

- What is the impact on overall electricity use of policies that provide efficiency incentives to different sectors?

- For efficiency measures that are incentivized in each sector, what is the level of adoption by 2040 needed to achieve specific electricity savings targets?

- Which efficiency measures within each sector will have the greatest impact on cumulative long-term electricity consumption?

\subsection{Tool Baseline Data}

PREESAT uses electricity sales forecasts from PREPA's 2019 IRP as its baseline business-asusual (BAU) scenarios. The IRP presents three different forecasts for 2019-2038: high, medium, and low electricity use cases. These were developed using a multivariable linear regression model, which is a commonly used method in developing energy use forecasts. In the IRP's own analysis, the variables found to have the highest statistically significant correlation for each sector were: 
- Residential: cooling degree days, gross national product, population, month of the year

- Commercial: cooling degree days, gross national product, month of the year

- Industrial: cooling degree days, gross national product, manufacturing employment, and month of the year.

The IRP sourced historical and forecasted gross national product, population data, and manufacturing employment data from projections by the Financial Oversight and Management Board for Puerto Rico. The Siemens consultants who authored the IRP used a stochastic distribution that included both parametric and quantum distributions to develop various scenarios, incorporating future uncertainties for economic and demographic trends (Siemens 2019). The $25^{\text {th }}$ percentile was taken to represent the low electricity consumption forecast and the $85^{\text {th }}$ percentile was taken to represent the high electricity consumption forecast. NREL extrapolated these forecasts, which end in 2038, to 2040, which is the year referenced in the P.L. 17-2019 energy efficiency target. The low, medium, and high baseline BAU forecasts predict a $10 \%$ decrease, $4 \%$ decrease, and an $8 \%$ increase in annual electricity consumption, respectively, by 2040 compared to estimated 2020 levels (Figure 3).

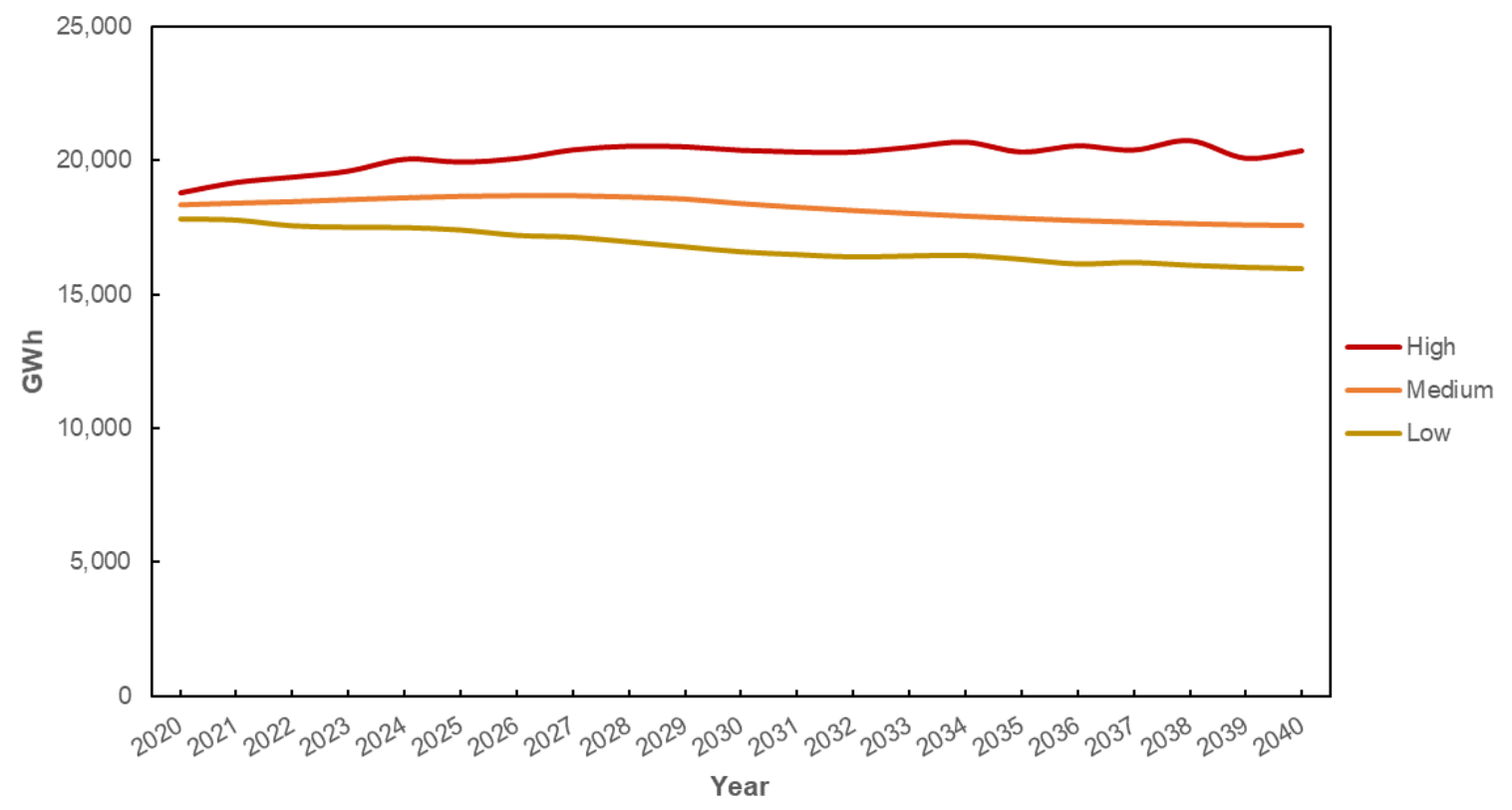

Figure 3. PREESAT baseline BAU electricity consumption forecasts, 2020-2040

These forecasts are also broken down per sector: residential, commercial, industrial, and street lighting. Agriculture and other uses, which made up only $0.4 \%$ of electricity consumption in 2018, are omitted from the baseline. In PREESAT, users can either select which of these three baseline BAU forecasts to use or enter a different or custom baseline. Although P.L. 17-2019 itself does not specify a baseline for the 2040 energy efficiency target, PREB clarified in its April 2021 proposed energy efficiency regulation that this baseline is PREPA's FY19 sales, which were approximately 15,813 GWh. PREESAT displays both the percentage reduction from the selected BAU forecast and from the PREB-specified baseline. 


\section{PREESAT Dashboard}

Users navigate PREESAT using four main tabs: dashboard, residential, commercial, and industrial.

The first tab in PREESAT is the dashboard, which is pictured in Figure 4. The dashboard summarizes key results in tables and charts based on various inputs: the baseline BAU electricity consumption forecasts and the estimated electricity consumption reductions that are due to efficiency measures from the residential, commercial, and industrial tabs.

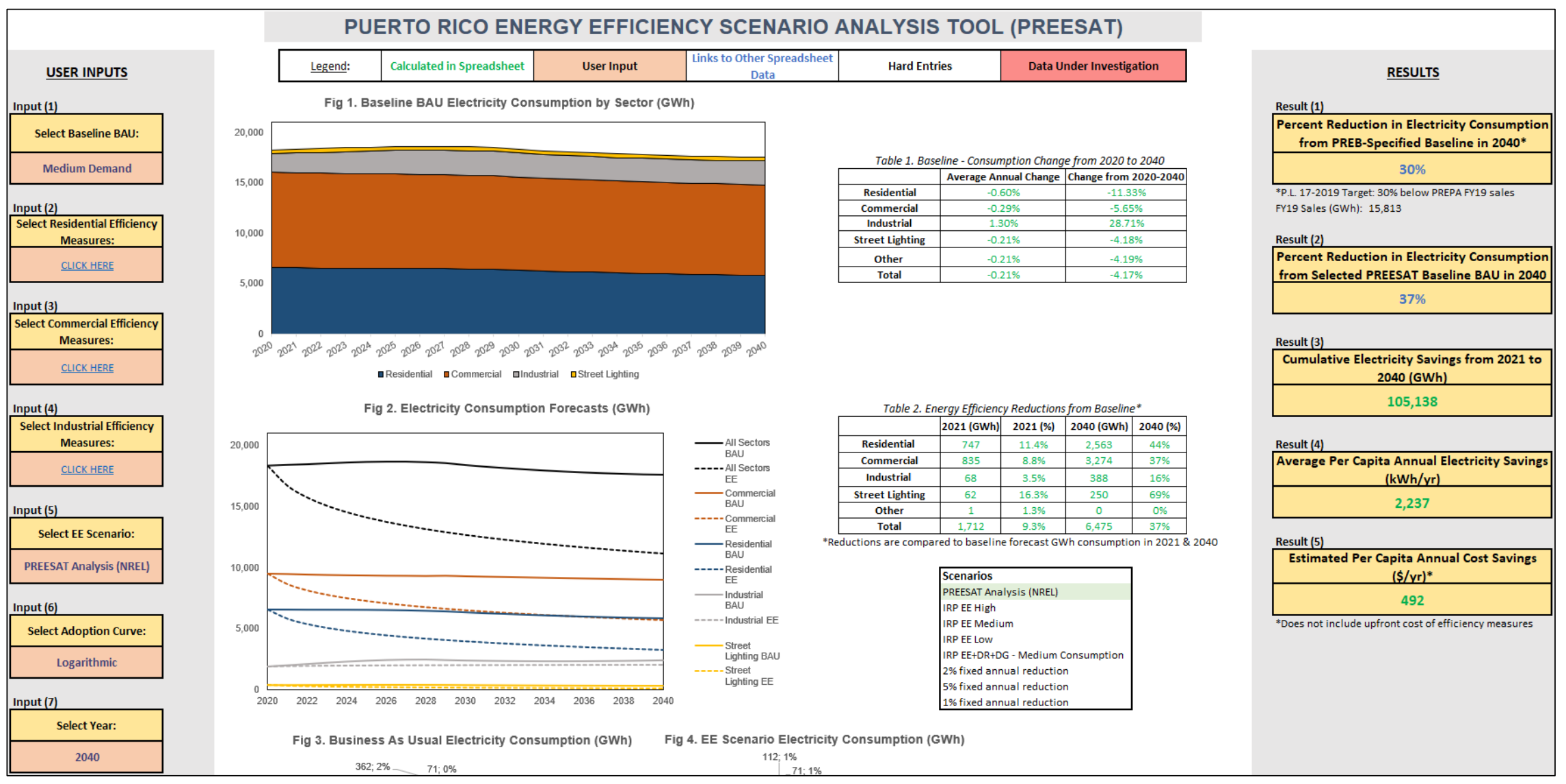

Figure 4. PREESAT dashboard 
The panels on the left of the dashboard contains the various user inputs and the panels on the right of the dashboard summarizes the key results based on these inputs (Figure 5).

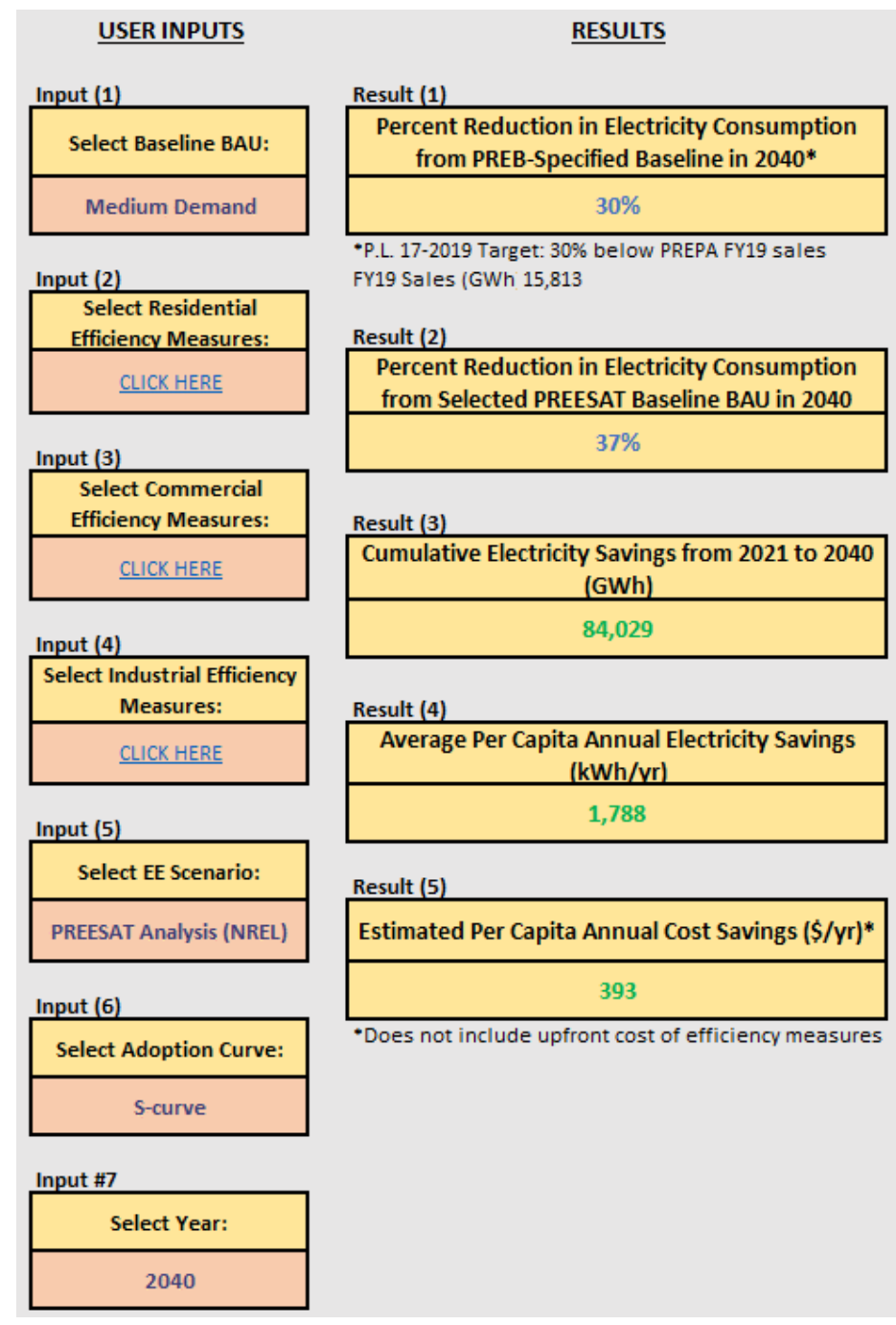

Figure 5. PREESAT dashboard user inputs and results

\subsection{User Inputs}

Input 1 (Select Baseline BAU) prompts users to choose the High Demand, Medium Demand, or Low Demand baseline BAU electricity consumption forecasts from 2020 to 2040, which were detailed in Section 2.3. The selected option, which is displayed on the dashboard (Figure 6), is the baseline against which electricity consumption reductions are calculated for each year. These reductions are based on Inputs 2-4 in Figure 5, which allow users to select residential, commercial, and industrial efficiency measures and their corresponding adoption percentages on subsequent tabs within PREESAT. The energy-savings assumptions for each efficiency measure are based on relevant data and sources. With Input 5 (Select EE Scenario), users can choose whether to display results calculated from PREESAT or instead compare other energy efficiency (EE) scenarios against the baseline, such as the IRP EE forecasts or a constant percentage reduction in electricity usage. 


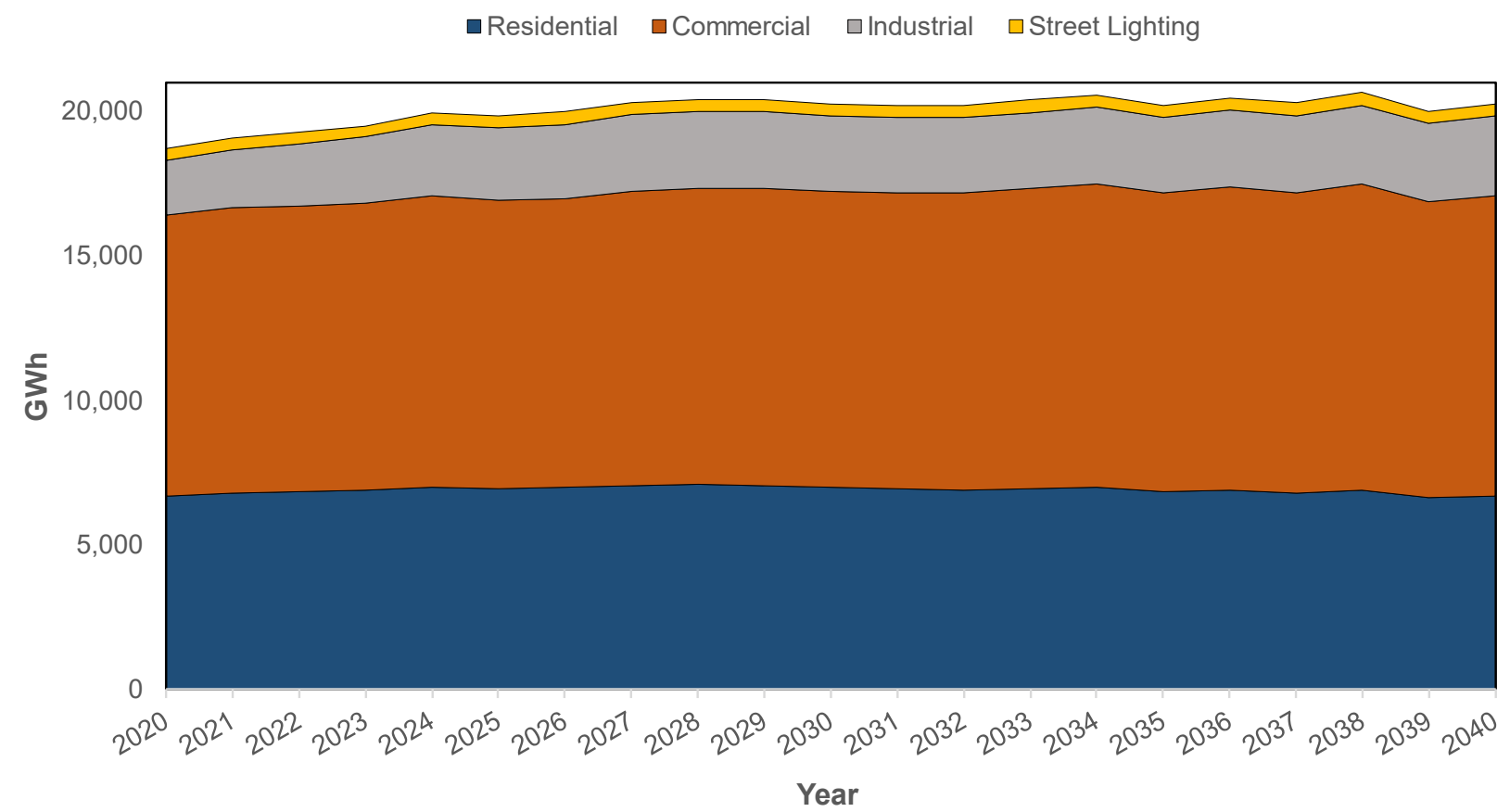

Figure 6. High Demand baseline BAU electricity consumption forecast by sector, 2020-2040

For Input 6 in Figure 5, users can select an adoption curve profile over time (i.e., straight-line, Scurve, or logarithmic). A straight-line adoption profile assumes a constant rate of adoption from 2020 levels to the user-specified 2040 levels. An S-curve profile assumes rates of adoption will be slower in the early years (2020-2026), increase in the middle years (2027-2035), and then taper out in the later years (2036-2040). A logarithmic adoption profile assumes the rates of adoption will be highest in the early ears (2020-2026) before steady decreasing until 2040. The selected EE scenario, which is based on all these inputs, is displayed against the BAU scenario and is broken down by sector (Figure 7). 


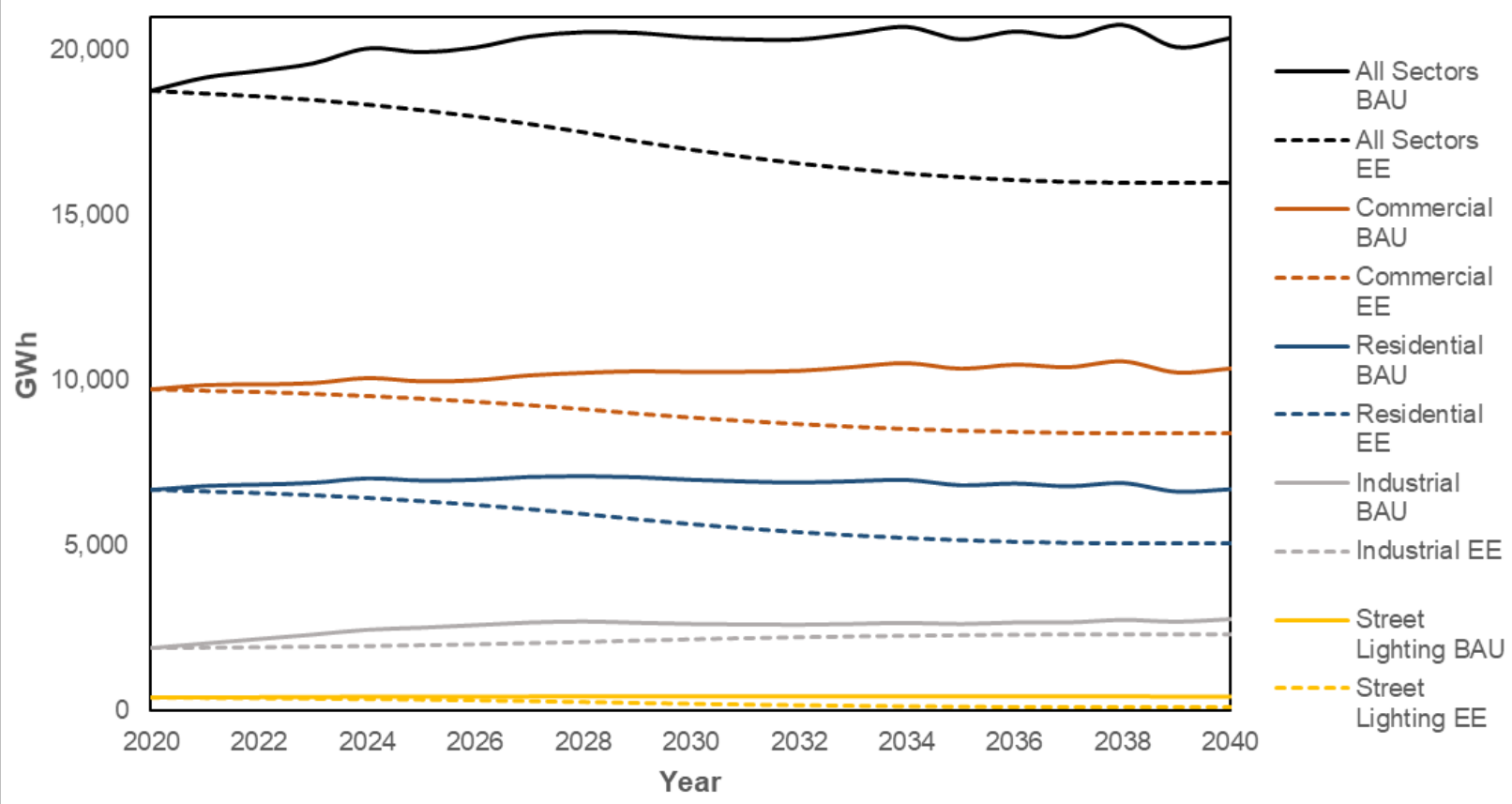

Figure 7. Electricity consumption forecasts for High Demand baseline BAU, hypothetical PREESAT Analysis (NREL) EE scenario, and S-curve adoption profile for efficiency measures

Street lighting efficiency is not adjusted within the tool, so the PREESAT Analysis (NREL) scenario for street lighting uses the IRP EE Medium scenario projections for street lighting electricity consumption. Users can input custom street lighting forecasts in the Consumption Forecasts tab of PREESAT. For Input 7 in Figure 5, users can select a year from 2020 to 2040 to view a detailed comparison of the BAU and EE scenarios for that year (Figure 8).
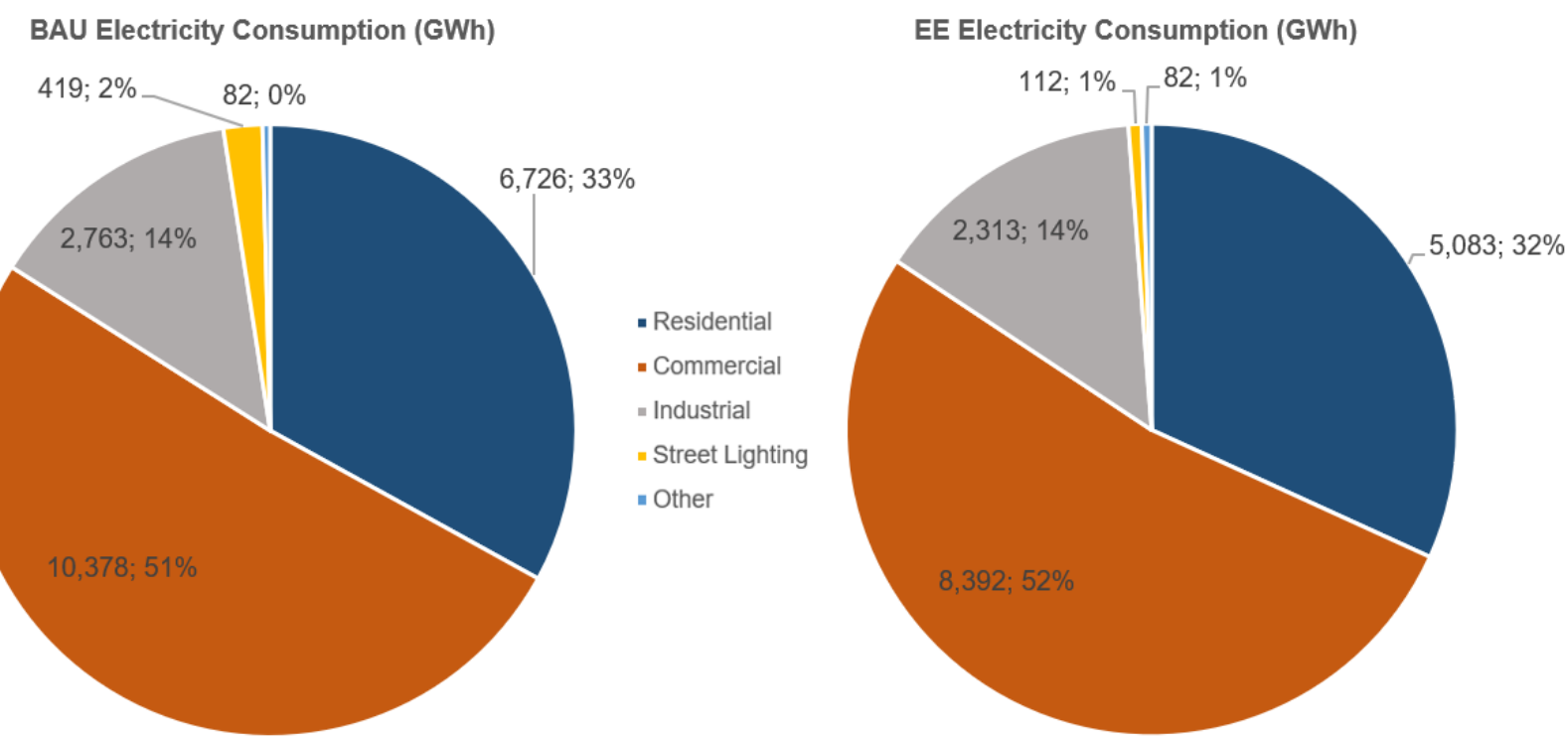

Figure 8. Baseline BAU versus EE scenario electricity consumption breakdown by sector, 2040 


\subsection{Results}

These results on the PREESAT dashboard are (1) percentage reduction in electricity consumption from PREB-specified baseline in 2040, (2) percentage reduction in electricity consumption from selected PREESAT baseline BAU in 2040, (3) cumulative electricity savings from 2021 to 2040, (4) average per capita annual electricity savings, and (5) estimated per capita annual cost savings (Figure 5).

Result 1 is important in the context of P.L. 17-2019, which targets a 30\% reduction in this value. Result 5 does not consider the upfront costs associated with implementing the efficiency measures, and it assumes a retail electricity rate of $\$ 0.22 / \mathrm{kWh}$. Decision makers can explore energy efficiency pathways to reach the P.L. 17-2019 target or can explore pathways to achieve other targets based on a BAU baseline (Result 2), cumulative electricity savings (Result 3 ) or per capita annual cost savings (Result 5) depending on their objectives.

\section{The Residential Sector Measures in PREESAT}

The approximately 1.3 million residential customers in Puerto Rico used 6,051 GWh of electricity in 2018, which accounted for around $37 \%$ of the annual electricity consumption in Puerto Rico (Siemens 2019). There is a large percentage of low-income customers in the territory, with $43.5 \%$ of the population living in poverty and an area annual median income of $\$ 20,539 .{ }^{2}$ Typical residential building structures are concrete block or poured concrete constructions. Multifamily housing units, which are common, typically consist of 2--4 families living in different units in the same structure. The PREESAT residential tab combines these single-family and multifamily residential efficiency measures.

The U.S. Virgin Islands Energy Efficiency Tool (USVIEET), developed by the U.S. Department of Energy (DOE) Islands Energy Initiative, was used as a proxy to determine the top energy end uses for the residential sector in PREESAT. Section 4.2 describes the data sources in detail and their applicability to Puerto Rico. The eight categories of residential end uses in the USVIEET data set are water heating, fans, lighting, TV, refrigeration, air conditioning (AC), cooking, and clothes drying (Figure 9). Expert interviews confirmed that the majority of households in Puerto Rico use electric tank water heaters rather than propane or solar water heaters. Cooling is primarily provided by standing or ceiling fans, as $\mathrm{AC}$ is not ubiquitous, particularly in lowincome households. When present, AC typically takes the form of window units.

\footnotetext{
2 “QuickFacts: Puerto Rico,” U.S. Census Bureau, https://www.census.gov/quickfacts/PR, accessed June 8, 2021.
} 


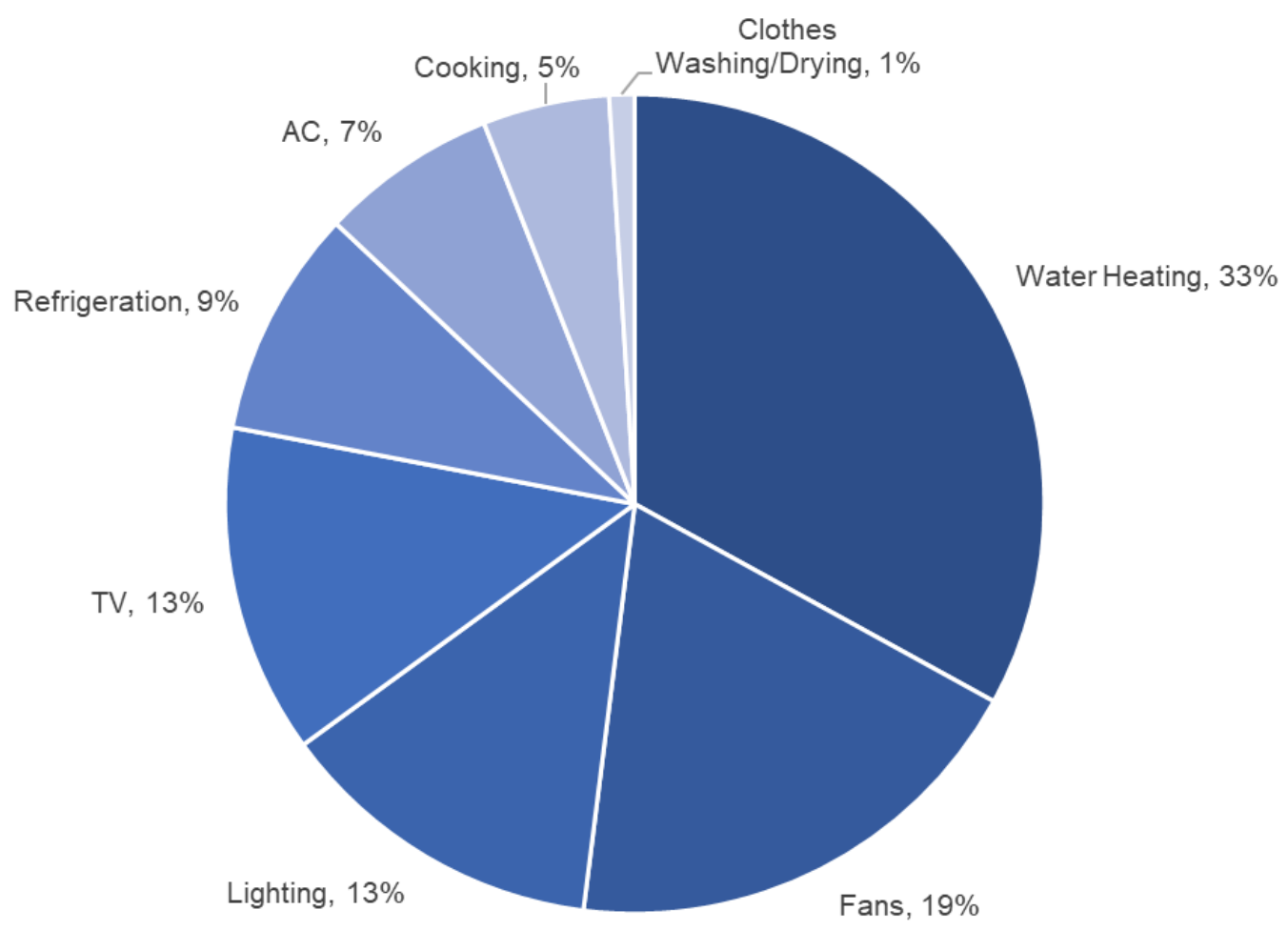

Figure 9. PREESAT residential tab electricity consumption breakdown by end use

\subsection{Residential Sector Data and Assumptions}

The data in the PREESAT residential tab are a compilation of energy efficiency savings estimates. The main sources are the USVIEET tool described in Section 4.1, the PREPA IRP, the Puerto Rico Energy Audit Tool developed by the DOE Weatherization Assistance Program, the ResStock $^{\mathrm{TM}}$ analysis tool for Florida developed by NREL, and a Puerto Rico Stakeholder Workshop in 2020. Of these, USVIEET is the most comprehensive data set. Although USVIEET is for the neighboring U.S. Virgin Islands and not Puerto Rico, several interviewees acknowledged residential building construction and lifestyle habits are fairly similar between the two territories. Ideally, PREESAT would incorporate a recent sample of residential energy audits from Puerto Rico, but this information either does not exist or was unavailable.

\subsection{PREESAT Residential Tab: User Guidance}

The PREESAT residential tab allows users to select different energy efficiency measures and view the resulting sector-specific percentage reduction in electricity consumption in 2040 compared to the baseline (Figure 10, page 12). Column 1 organizes specific energy efficiency measures by the following end-use categories: AC, lighting, water heating, fans, envelope, refrigeration, clothes washing, clothes drying, TV, education/outreach, faucet aerators, low-flow showerheads, dishwashers, cooking, plug loads, advanced metering, dehumidification, and daylighting. Users can also add new end-use categories and efficiency measures.

PREESAT has an estimated percentage of total residential electricity consumption for each enduse category (Column 2) and a default estimate for the annual electricity savings per customer for each specific measure (Column 3); both are based on the data sources described in Section 4.2. 
In Column 4, users can specify the number of residential customers who will adopt or be eligible for a specific measure as percentage of the total number of residential customers who adopt any efficiency measure within the particular end-use category. For each end-use category, the percentages in Column 4 should always total $100 \%$, as the specific energy efficiency measures within a particular end-use category are assumed to be mutually exclusive. In Column 5, users can select the percentage of residential customers who adopt any efficiency measure within the particular end-use category over the 2020-2040 forecast horizon.

The values in Columns 6-8 are calculated using the values in Columns 1-5. Column 6 represents the absolute electricity savings in 2040 (compared to the baseline) that are due to the corresponding energy efficiency measures. Column 7 represents the percentage reduction in enduse electricity consumption in 2040 (compared to the baseline) that is due to the corresponding energy efficiency measures. Column 8 represents the percentage reduction of total residential electricity consumption in 2040 (compared to the baseline) that is due to the corresponding energy efficiency measures. The values in Column 8 are aggregated to determine the result in the Total Percentage Reduction in Residential Electricity Consumption in 2040 Compared to Baseline box at the top of the tab; this value is fed into the PREESAT dashboard summary calculations.

An example of the values for Columns 1-8, specifically for the end use of AC, is shown in Figure 11 (page 13). As indicated in Column 2, AC accounts for $7 \%$ of total residential electricity consumption. The first energy efficiency measure listed (Upgrade Window Unit from SEER 8.5 to SEER 12$)^{3}$ results in an annual electricity savings of $1,106 \mathrm{kWh}$ per customer as indicated in Column 3. In Column 4, users determine that $40 \%$ of all residential customers who adopt any type of AC-related efficiency measure will specifically choose the Upgrade Window Unit from SEER 8.5 to SEER 12 measure. In Column 5, users specify that $10 \%$ of all residential customers will adopt some type of AC-related efficiency measure by 2040, regardless of the specific measure.

\footnotetext{
${ }^{3}$ SEER $=$ Seasonal Energy Efficiency Ratio
} 


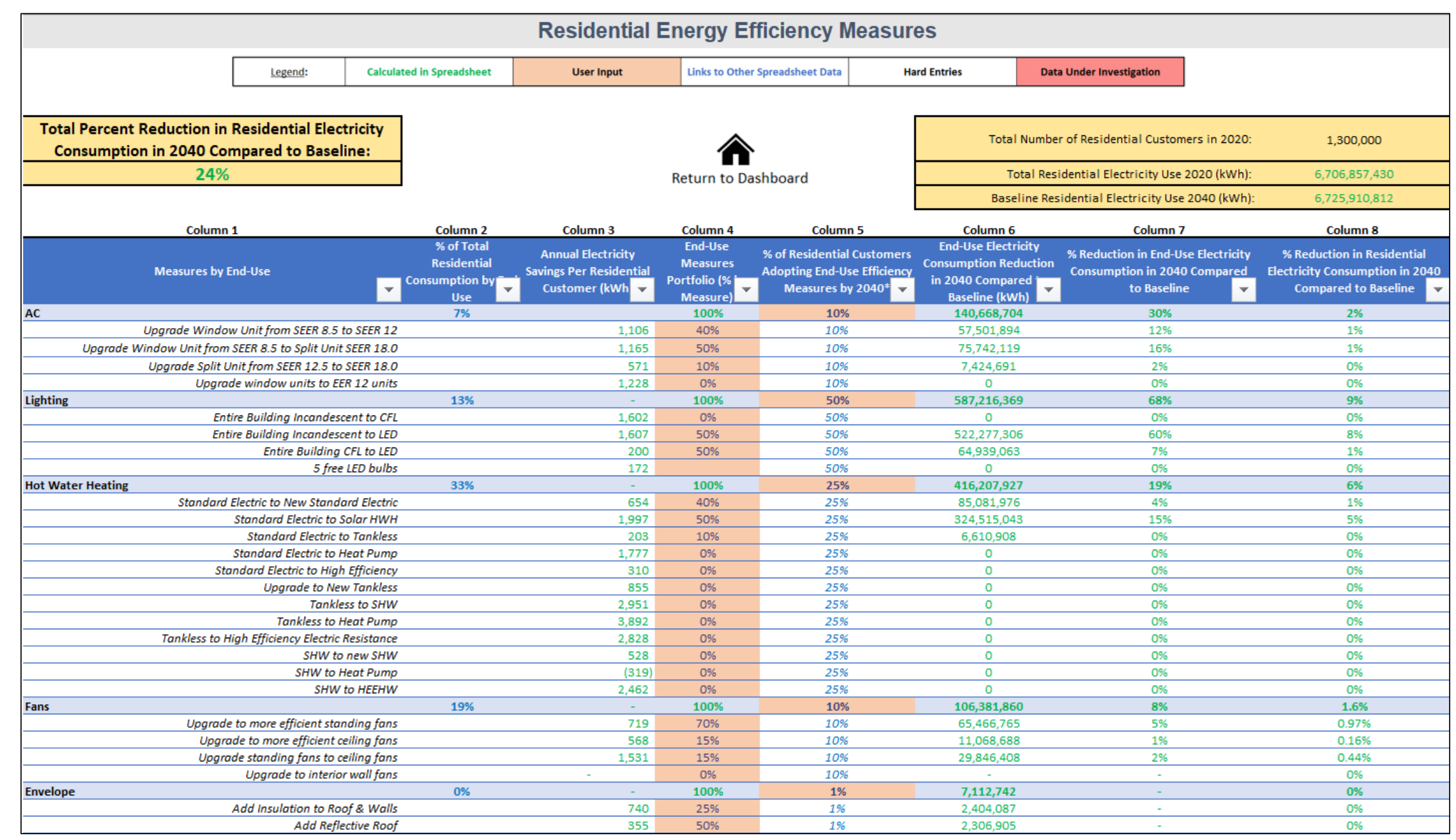

Figure 10. PREESAT residential tab 


\begin{tabular}{|c|c|c|c|c|c|c|c|}
\hline Column 1 & Column 2 & Column 3 & Column 4 & Column 5 & Column 6 & Column 7 & Column 8 \\
\hline Measures by End-Use & $\begin{array}{l}\% \text { of Total Residential } \\
\text { Consumption by End- }\end{array}$ & $\begin{array}{c}\text { Annual Electricity } \\
\text { Savings Per Residential }\end{array}$ & $\begin{array}{c}\text { End-Use Measures } \\
\text { Portfolio (\% by }\end{array}$ & $\begin{array}{l}\% \text { of Residential Customers } \\
\text { Adopting End-Use Efficiency }\end{array}$ & $\begin{array}{l}\text { End-Use Electricity } \\
\text { Consumption Reduction in } \\
2040 \text { Compared to }\end{array}$ & $\begin{array}{l}\text { \% Reduction in End-Use } \\
\text { Electricity Consumption in } 2040\end{array}$ & $\begin{array}{l}\text { \% Reduction in Residential } \\
\text { Electricity Consumption in } 2040\end{array}$ \\
\hline$\checkmark$ & Use $\quad \nabla$ & Customer (kWh) & Measure) & Measures by $2040^{*}$ & $\begin{array}{c}{ }_{1}^{2040} \text { Compared to } \\
\text { Baseline (kWh) }\end{array}$ & Compared to Baseline $\nabla$ & Compared to Baseline $\nabla$ \\
\hline AC & $7 \%$ & & $100 \%$ & $10 \%$ & $140,668,704$ & $30 \%$ & $2 \%$ \\
\hline Upgrade Window Unit from SEER 8.5 to SEER 12 & & 1,106 & $40 \%$ & $10 \%$ & $57,501,894$ & $12 \%$ & $1 \%$ \\
\hline Upgrade Window Unit from SEER 8.5 to Split Unit SEER 18.0 & & 1,165 & $50 \%$ & $10 \%$ & $75,742,119$ & $16 \%$ & $1 \%$ \\
\hline Upgrade Split Unit from SEER 12.5 to SEER 18.0 & & 571 & $10 \%$ & $10 \%$ & $7,424,691$ & $2 \%$ & $0 \%$ \\
\hline Upgrade window units to EER 12 units & & 1,228 & $0 \%$ & $10 \%$ & 0 & $0 \%$ & $0 \%$ \\
\hline
\end{tabular}

Figure 11. PREESAT residential tab efficiency measures for AC end use

Column 6 calculates that the Upgrade Window Unit from SEER 8.5 to SEER 12 measure - which is based on its electricity savings potential in Column 3 and the user-specified adoption rates in Columns 4 and 5-will result in an electricity consumption reduction of about 57,501,894 kWh in 2040, compared to the baseline (Figure 12). The result from Column 6 translates to a 12\% reduction in AC electricity consumption and a $1 \%$ reduction in total residential electricity consumption in 2040 compared to the baseline. These percentages are displayed in Columns 7 and 8 respectively.

\begin{tabular}{|c|c|c|c|c|}
\hline $\begin{array}{c}\text { Annual Electricity } \\
\text { Savings per Customer } \\
\text { (Column 3) }\end{array}$ & $\begin{array}{c}\text { Portfolio } \\
\text { Percentage } \\
\text { (Column 4) }\end{array}$ & $\begin{array}{l}\text { Level of } \\
\text { Adoption } \\
\text { (Column 5) }\end{array}$ & $\begin{array}{l}\text { Number of } \\
\text { Residential } \\
\text { Customers }\end{array}$ & $\begin{array}{l}\text { Electricity } \\
\text { Savings } \\
\text { (Column 6) }\end{array}$ \\
\hline $\begin{array}{l}1,106 \mathrm{kWh} / \mathrm{yr} \text {. savings per } \\
\text { customer for upgrading } \\
\text { AC window unit from } \\
\text { SEER } 8.5 \text { to SEER } 12\end{array}$ & $\begin{array}{c}40 \% \text { of } A C \\
\text { upgrades } \\
\text { take this } \\
\text { measure }\end{array}$ & $\begin{array}{l}10 \% \text { of } \\
\text { residential } \\
\text { customers } \\
\text { upgrade } A C\end{array}$ & $\begin{array}{l}1.3 \mathrm{~m} \\
\text { residential } \\
\text { customers in } \\
\text { Puerto Rico }\end{array}$ & $\begin{array}{c}57,501,894 \\
\text { kWh/yr. of } \\
\text { electricity } \\
\text { savings }\end{array}$ \\
\hline
\end{tabular}

Figure 12. Calculation of electricity savings in 2040 (compared to the baseline) that are due to user-specified adoption levels for the Upgrade Window Unit from SEER 8.5 to SEER 12 measure 


\subsection{Residential Sector Analysis}

We analyzed energy efficiency measures for Puerto Rico's residential sector using PREESAT in order to identify electricity and cost savings opportunities (Avilés et al. 2020). Water heating consumes the most electricity in this sector and upgrading a less efficient electric tank water heater to a solar water heater presents the greatest water heating savings opportunity. However, upgrading to a solar water heater might pose difficulties for multifamily housing units, unless multiple sets of collectors could be located on one roof. Another option is replacing the electric tank water heater with a heat pump water heater.

Residential cooling, provided primarily by fans and AC systems, is the second-largest consumer of electricity in this sector. Of all cooling measures, upgrading window AC units to more efficient models or to mini-split units results in the largest electricity consumption reduction despite the lower prevalence of AC in residences. This is because AC consumes more electricity than other cooling systems. Replacing standing fans with ceiling fans also results in significant electricity savings based on our PREESAT analysis. However, it is important to note that we did not consider differences in occupant behavior.

For lighting, which is the third-largest consumer of electricity in Puerto Rico's residential sector, the most impactful measure is switching from incandescent bulbs to LED fixtures. Upgrades to building envelopes, such as installing low-E storm windows, window shades, insulation, and cool roofs, are also key efficiency measures for households, as these actions would reduce AC or fan energy consumption; this is especially important as old structures are replaced with new ones.

Though we did not analyze them, PREESAT can also be used to analyze efficiency interventions related to refrigeration, cooking, education, and major plug loads such as TVs.

\section{The Commercial Sector Measures in PREESAT}

In 2018, the commercial sector's 121,515 customers used 7,758 GWh of electricity, which was more than any other sector and accounted for $47 \%$ of total electricity use in Puerto Rico (IRP 2019). This sector consists of offices, hotels, restaurants, markets, retail establishments, and other places of business. Based on local expert interviews, the building characteristics and energy consumption patterns in Puerto Rico's commercial sector are comparable to that of commercial sectors in similar climates in the continental United States. In PREESAT, the main electricity end uses for this sector are heating, ventilation, and air conditioning (HVAC), equipment, lighting, and refrigeration (Figure 13). These data are sourced according to the calculations described in Section 5.2. 


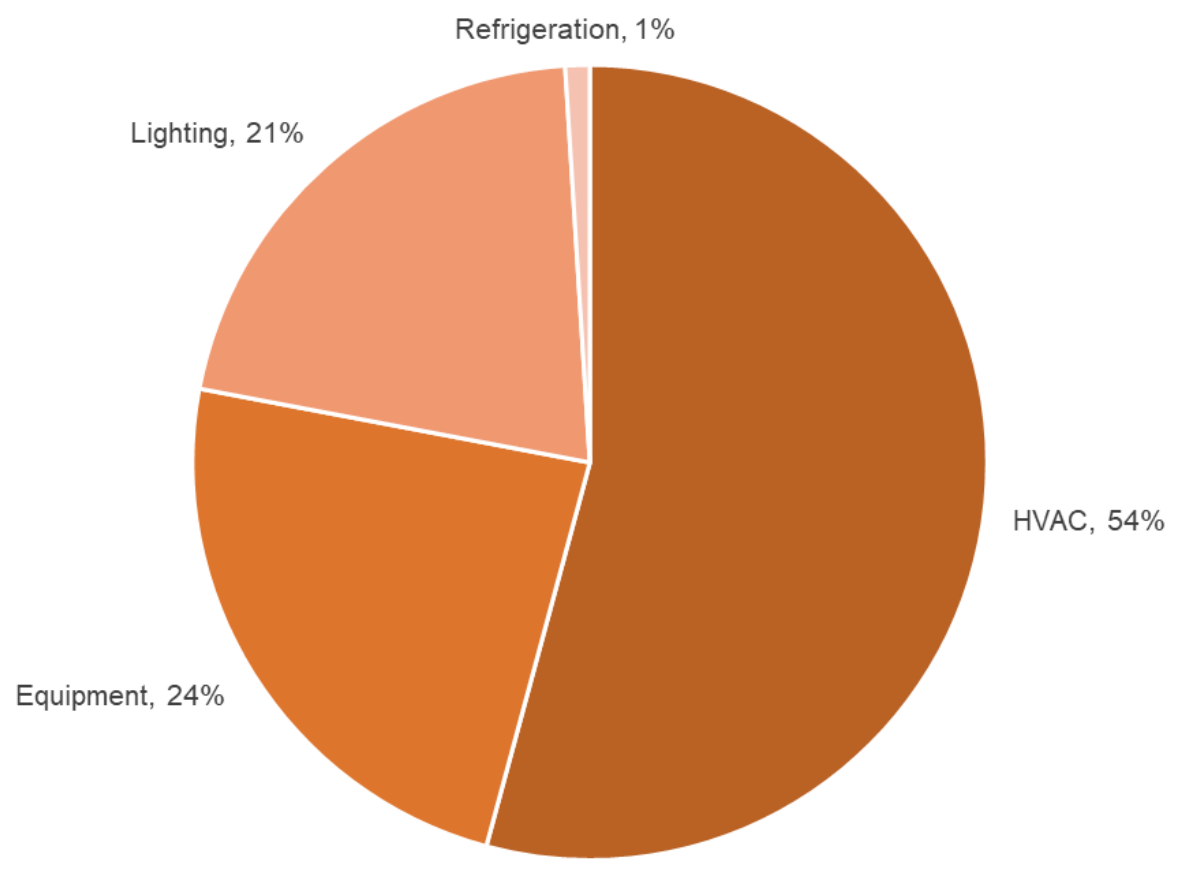

Figure 13. PREESAT commercial tab electricity consumption breakdown by end use

\subsection{Commercial Sector Data and Assumptions}

We found the commercial sector in Puerto Rico to have the least available and reliable local data. Based on this reality and expert interviews, PREESAT pulls its default commercial assumptions from sources in the southeastern United States, the continuous U.S. region with the most similar climate. PREESAT uses the DOE Commercial Reference Buildings model set, as well as Scout, ${ }^{4}$ a tool developed by the DOE "for estimating the energy and carbon impacts of various energy conservation measures (ECMs) on the U.S. residential and commercial building sectors."

To determine the electricity consumed for different end uses (e.g., cooling and lighting) per building type (e.g., offices and hotels), PREESAT uses the Commercial Reference Buildings model set for Miami. The building types are adjusted to match the building types used in Scout. PREESAT then estimates the total percentage of electricity consumption for each commercial end use by weighting the total square footage of each building type. Figure 14 (page 16) shows how the average electricity consumption for different end uses of each building type is weighted by the approximate square footage of each building type in the climate zone. The final breakdown of electricity consumption by end use across the sector is highlighted in yellow.

To estimate electricity savings from various energy efficiency measures, PREESAT uses specific measures and predicted percentage savings from the Scout tool for the entire American Institute of Architects Climate Zone 5, which is the southernmost climate zone in the continental United States. These results are then sorted by end use and filtered to exclude irrelevant measures such as heating

\footnotetext{
${ }^{4}$ Scout, DOE, https://scout.energy.gov, accessed 2020.
} 


\begin{tabular}{|c|c|c|c|c|c|c|c|c|c|c|c|c|c|c|}
\hline \multicolumn{15}{|c|}{ ScOUT Building Type } \\
\hline & & Assembly & Education & Food Sales & Food Service & Health Care & Large Office & Lodging & Mercantile/Service & Other & Small Office & Warehouse & \multirow{3}{*}{$\begin{array}{c}\text { WEIGHTED } \\
\text { AVERAGE ENERGY } \\
\text { USE }\end{array}$} & \multirow{3}{*}{ \% OF TOTAL } \\
\hline \multicolumn{2}{|c|}{$\%$ of total sqft in AIA Climate } & & & & & & & & & & & & & \\
\hline & Zone 5 --> & $11 \%$ & $16 \%$ & $1 \%$ & $2 \%$ & $3 \%$ & $7 \%$ & $6 \%$ & $18 \%$ & $10 \%$ & $10 \%$ & $16 \%$ & & \\
\hline \multirow{15}{*}{ 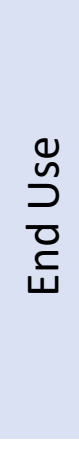 } & Heating & $5,887,782$ & $2,395,317$ & 148,116 & 81,461 & $3,318,536$ & $2,966,490$ & $3,586,175$ & 163,843 & $1,224,737$ & 662,848 & 37,037 & 1,144 & $0 \%$ \\
\hline & Cooling & $2,092,487$ & 937,437 & 388,020 & 64,116 & $1,150,274$ & $1,997,230$ & 497,472 & 251,558 & 521,461 & 186,208 & 101,129 & $1,767,640$ & $47 \%$ \\
\hline & Interior Lighting & 86,335 & 79,711 & 69,247 & 18,718 & 78,965 & 241,700 & 99,757 & 49,258 & 68,406 & 64,406 & 46,118 & 718,576 & $19 \%$ \\
\hline & Exterior Lighting & $1,817,169$ & 557,069 & 218,247 & 150,068 & $1,158,474$ & $2,125,621$ & 459,942 & 48,764 & 466,086 & 442,729 & 29,006 & 78,800 & $2 \%$ \\
\hline & Interior Equipment & 694,292 & - & - & - & 347,146 & 473,770 & 194,772 & - & 92,744 & - & - & 606,874 & $16 \%$ \\
\hline & Exterior Equipment & $1,047,261$ & 356,319 & 138,845 & 44,513 & 663,567 & 206,201 & 274,478 & 95,244 & 191,506 & 248,373 & 35,189 & 139,338 & $4 \%$ \\
\hline & Fans & 515,709 & 9,764 & - & - & 260,794 & 291,051 & 22,571 & - & 55,566 & 5,173 & - & 286,222 & $8 \%$ \\
\hline & Pumps & 357,363 & - & - & - & 178,681 & 227,855 & - & - & 38,158 & - & - & 91,956 & $2 \%$ \\
\hline & Heat Rejection & 7,182 & - & - & - & 4,318 & - & - & - & 540 & 1,279 & - & 63,142 & $2 \%$ \\
\hline & Humidification & - & - & - & - & - & - & - & - & - & - & - & 1,048 & $0 \%$ \\
\hline & Heat Recovery & - & - & - & - & - & - & - & - & - & - & - & - & $0 \%$ \\
\hline & Water Systems & 56,966 & 38,041 & $1,252,803$ & 18,870 & 28,483 & - & 16,271 & - & 89,701 & - & - & - & $0 \%$ \\
\hline & Refrigeration & - & - & - & - & - & - & - & - & - & - & - & 37,722 & $1 \%$ \\
\hline & Generators & - & - & - & - & - & - & - & - & - & - & - & - & $0 \%$ \\
\hline & & & & & & & & & & & & SUM TOTAL --> & $3,792,464$ & $100 \%$ \\
\hline
\end{tabular}

Figure 14. Calculation of relative electricity consumption of different commercial end use

\subsection{PREESAT Commercial Tab: User Guidance}

The PREESAT commercial tab allows users to select different efficiency measures and view the resulting sector-specific percentage reduction in electricity consumption in 2040 compared to the baseline (Figure 15). Column 1 organizes specific energy efficiency measures by the following end-use categories: HVAC, lighting, hot water heating, refrigeration, envelope, sensors and controls, equipment, and "other." The specific measures under each end use either were taken from the Scout database or were incorporated after stakeholder feedback. Users can also add end-use categories and efficiency measures. Column 2 lists the estimated percentage of total commercial electricity consumption for each end-use category, as calculated in Section 5.2. Column 3 lists the estimated percentage savings in electricity consumption compared to the baseline for each corresponding efficiency measure. These values are taken from Scout's database for the American Institute of Architects Climate Zone 5. In Column 4, users can specify the percentage of commercial customers who will adopt or be eligible for a specific measure, out of the total number of commercial customers who adopt any efficiency measure within the particular end-use category. For each enduse category, the percentages in Column 4 should always add up to $100 \%$, as the specific energy efficiency measures within a particular end-use category are assumed to be mutually exclusive. In Column 5, users can select the percentage of commercial customers who adopt any efficiency measure within the particular end-use category over the 2020-2040 forecast horizon. The values in Columns 6 and 7 are calculated using the values in Columns 1-5. Column 6 represents the absolute electricity savings in 2040 (compared to the baseline) that are due to the corresponding energy efficiency measures. 


\begin{tabular}{|c|c|c|c|c|c|c|c|}
\hline \multicolumn{8}{|c|}{ Commercial Energy Efficiency Measures } \\
\hline Legend: & Calculated in Spreadsheet & & User Input & Links to Other Spreadsheet Data & Hard Entries & Data Under Investigation & \\
\hline $\begin{array}{l}\text { Total Percent Reduction in Commercial Electricity } \\
\text { Consumption in } 2040 \text { Compared to Baseline: }\end{array}$ & & & \multirow{3}{*}{\multicolumn{2}{|c|}{ Return to Dashboard }} & \multicolumn{2}{|c|}{ Total Number of Commercial Customers in 2020: } & 121,515 \\
\hline \multirow[t]{2}{*}{$19 \%$} & & & & & \multicolumn{2}{|c|}{ Total Commercial Electricity Use $2020(\mathrm{kWh}):$} & $9,726,287,010$ \\
\hline & & & & & \multicolumn{2}{|c|}{ Baseline Commerical Electricity Use 2040 (kWh): } & $10,378,305,341$ \\
\hline Column 1 & Column 2 & Column 3 & Column 4 & Column 5 & Column 6 & Column 7 & Column 8 \\
\hline Measures by End-Use & $\begin{array}{l}\text { \% of Total Commercial \% EI } \\
\text { Consumption by End- } \\
\text { Use }\end{array}$ & $\begin{array}{l}\text { lectricity Savings } \\
\text { Compared to } \\
\text { Baseline }\end{array}$ & $\begin{array}{l}\text { gs End-Use Measures } \\
\text { Portfolio (\% by } \\
\text { Measure) }\end{array}$ & $\begin{array}{l}\text { \% of Commercial Customers } \\
\text { Adopting End-Use Efficiency } \\
\text { Measures by } 2040^{*}\end{array}$ & $\begin{array}{l}\text { End-Use Electricity Consumption } \\
\text { Reduction in } 2040 \text { Compared to } \\
\text { Baseline (kWh) }\end{array}$ & $\begin{array}{l}\text { \% Reduction in End-Use } \\
\text { Electricity Consumption in } 2040 \\
\text { Compared to Baseline }\end{array}$ & $\begin{array}{l}\text { \% Reduction in Commercial } \\
\text { Electricity Consumption in } 2040 \\
\text { Compared to Baseline }\end{array}$ \\
\hline HVAC & $54 \%$ & & $100 \%$ & $40 \%$ & $326,749,929$ & $6 \%$ & $3 \%$ \\
\hline Best Commercial Rooftop AC & & $16 \%$ & $25 \%$ & $40 \%$ & $87,544,540$ & $2 \%$ & $1 \%$ \\
\hline Commercial Chillers, 90.1 c. 2016 & & $13 \%$ & $25 \%$ & $40 \%$ & $75,660,841$ & $1 \%$ & $1 \%$ \\
\hline ENERGY STAR RTU V. 2.2 & & $11 \%$ & $25 \%$ & $40 \%$ & $61,376,755$ & $1 \%$ & $1 \%$ \\
\hline Best Rooftop Heat Pump & & $16 \%$ & $10 \%$ & $40 \%$ & $35,095,568$ & $1 \%$ & $0 \%$ \\
\hline ENERGY STAR Rooftop HP v. 2.2 & & $5 \%$ & $10 \%$ & $40 \%$ & $12,283,800$ & $0 \%$ & $0 \%$ \\
\hline Prospective Commercial AVCT HVAC & & $45 \%$ & $3 \%$ & $40 \%$ & $25,513,366$ & $0 \%$ & $0 \%$ \\
\hline Prospective Commercial NVC HVAC & & $52 \%$ & $3 \%$ & $40 \%$ & $29,275,059$ & $1 \%$ & $0 \%$ \\
\hline Add enthalpy wheels & & & & $40 \%$ & 0 & $0 \%$ & $0 \%$ \\
\hline Lighting & $21 \%$ & & $100 \%$ & $60 \%$ & $491,591,146$ & $23 \%$ & $5 \%$ \\
\hline Best Commercial LED Lighting & & $32 \%$ & $50 \%$ & $60 \%$ & $206,295,958$ & $9 \%$ & $2 \%$ \\
\hline ENERGY STAR Commercial LED Lighting & & $44 \%$ & $50 \%$ & $60 \%$ & $285,295,188$ & $13 \%$ & $3 \%$ \\
\hline Prospective Commercial SSL & & $62 \%$ & $0 \%$ & $60 \%$ & 0 & $0 \%$ & $0 \%$ \\
\hline Exterior Lighting - full cut off lamo posts & & & & $60 \%$ & 0 & $0 \%$ & $0 \%$ \\
\hline Hot Water Heating & $0 \%$ & & $100 \%$ & $5 \%$ & 0 & $0 \%$ & $0 \%$ \\
\hline ENERGY STAR Electric HPWH (Com.) & & $54 \%$ & $25 \%$ & $5 \%$ & 0 & $0 \%$ & $0 \%$ \\
\hline Prospective Commercial $\mathrm{CO} 2 \mathrm{HPWH}$ & & $70 \%$ & $25 \%$ & $5 \%$ & 0 & $0 \%$ & $0 \%$ \\
\hline Prospective Commercial Non-CO2 HPWH & & $65 \%$ & $25 \%$ & $5 \%$ & 0 & $0 \%$ & $0 \%$ \\
\hline Prospective Commercial NVC HPWH & & $46 \%$ & $25 \%$ & $5 \%$ & 0 & $0 \%$ & $0 \%$ \\
\hline Refrigeration & $1 \%$ & & $100 \%$ & $20 \%$ & $3,340,572$ & $3 \%$ & $0 \%$ \\
\hline Best Commercial Refrigeration & & $15 \%$ & $90 \%$ & $20 \%$ & $2,721,194$ & $3 \%$ & $0 \%$ \\
\hline Prospective Commercial Adv Refrigerator & & $28 \%$ & $5 \%$ & $20 \%$ & 289,043 & $0 \%$ & $0 \%$ \\
\hline Prospective Commercial NVC Refrigerator & & $32 \%$ & $5 \%$ & $20 \%$ & 330,335 & $0 \%$ & $0 \%$ \\
\hline 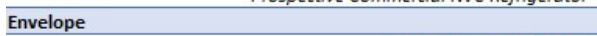 & $100 \%$ & & $100 \%$ & $20 \%$ & $898,052,339$ & $9 \%$ & $9 \%$ \\
\hline Best Commercial Roofs & & $12 \%$ & $10 \%$ & $20 \%$ & $25,420,246$ & $0 \%$ & $0 \%$ \\
\hline Best Commercial Walls & & $73 \%$ & $10 \%$ & $20 \%$ & $152,547,098$ & $1 \%$ & $1 \%$ \\
\hline Com. Air Sealing (Exist), 90.1 c. 2011 & & $73 \%$ & $15 \%$ & $20 \%$ & $228,322,717$ & $2 \%$ & $2 \%$ \\
\hline Commercial Fenestration, 90.1 c. 2016 & & $39 \%$ & $25 \%$ & $20 \%$ & $202,469,579$ & $2 \%$ & $2 \%$ \\
\hline Commercial Floors, 90.1 c. 2011 & & $0 \%$ & $10 \%$ & $20 \%$ & 0 & $0 \%$ & $0 \%$ \\
\hline Commercial Roofs, 90.1 c. 2016 & & $5 \%$ & $10 \%$ & $20 \%$ & $11,074,570$ & $0 \%$ & $0 \%$ \\
\hline Commercial Walls, 90.1 c. 2016 & & $67 \%$ & $20 \%$ & $20 \%$ & $278,218,128$ & $3 \%$ & $3 \%$ \\
\hline Daylighting - add Skylights or other & & & & $20 \%$ & $\frac{210,20,20}{0}$ & $0 \%$ & $0 \%$ \\
\hline Add shading & & & & $20 \%$ & 0 & $0 \%$ & $0 \%$ \\
\hline
\end{tabular}

\section{Figure 15. PREESAT commercial tab}


Column 7 represents the percentage reduction in end-use electricity consumption in 2040 from the baseline that is due to the corresponding energy efficiency measures. Column 8 represents the percentage reduction of total commercial electricity consumption in 2040 from the baseline that is due to the corresponding energy efficiency measures. The values in Column 8 are aggregated to determine the result in the Total Percentage Reduction in Commercial Electricity Consumption in 2040 Compared to Baseline box at the top of the tab. This value is fed into the PREESAT dashboard summary calculations.

An example of the values for Columns 1-8, specifically for the end use of HVAC, is shown in Figure 16 (page 19). As indicated in Column 2, HVAC accounts for approximately $54 \%$ of total commercial electricity consumption. The first efficiency measure listed (Best Commercial Rooftop AC) results in a 16\% reduction in electricity consumption as indicated in Column 3 . In Column 4 , users determine that $25 \%$ of all customers who adopt any type of HVAC-related efficiency measure will specifically choose the Best Commercial Rooftop AC measure. In Column 5 , users specify that $40 \%$ of all commercial customers will adopt some type of ACrelated efficiency measure by 2040 , regardless of the specific measure.

Column 6 calculates that the Best Commercial Rooftop AC measure-which is based on its electricity savings potential in Column 3 and the user-specified adoption rates in Columns 4 and 5-will result in an electricity consumption reduction of $87,544,540 \mathrm{kWh}$ in 2040 compared to the baseline (Figure 17). The result from Column 6 translates to a $6 \%$ reduction in HVAC electricity consumption and a $3 \%$ reduction in total commercial electricity consumption compared to the baseline in 2040, shown in Columns 7 and 8 . 


\begin{tabular}{|c|c|c|c|c|c|c|c|c|}
\hline & Column 1 & Column 2 & Column 3 & Column 4 & Column 5 & Column 6 & Column 7 & Column 8 \\
\hline & \multirow[t]{2}{*}{ Measures by End-Use } & $\begin{array}{l}\text { \% of Total Commercial } \\
\text { Consumption by End- }\end{array}$ & $\begin{array}{l}\text { \%Electricity Savings } \\
\text { compared to }\end{array}$ & $\begin{array}{l}\text { End-Use Measures } \\
\text { Portfolio (\% by }\end{array}$ & $\begin{array}{l}\text { \% of Commercial Customers } \\
\text { Adopting End-Use Efficiency }\end{array}$ & $\begin{array}{l}\text { End-Use Electricity Consumption } \\
\text { Reduction in } 2040 \text { Compared to }\end{array}$ & $\begin{array}{l}\text { \% Reduction in End-Use } \\
\text { Electricity Consumption in } 2040\end{array}$ & \multirow{2}{*}{$\begin{array}{l}\text { \% Reduction in Commercial } \\
\text { Electricity Consumption in } 2040 \\
\text { Compared to Baseline }\end{array}$} \\
\hline & & Use $\quad F$ & Baseline & Measure) & Measures by $2040^{*}$ & Baseline (kWh) & Compared to Baseline & \\
\hline HVAC & & $54 \%$ & & $100 \%$ & $40 \%$ & $326,749,929$ & $6 \%$ & $3 \%$ \\
\hline & Best Commercial Rooftop AC & & $16 \%$ & $25 \%$ & $40 \%$ & $87,544,540$ & $2 \%$ & $1 \%$ \\
\hline & Commercial Chillers, 90.1c. 2016 & & $13 \%$ & $25 \%$ & $40 \%$ & $75,660,841$ & $1 \%$ & $1 \%$ \\
\hline & ENERGY STAR RTU v. 2.2 & & $11 \%$ & $25 \%$ & $40 \%$ & $61,376,755$ & $1 \%$ & $1 \%$ \\
\hline & Best Rooftop Heat Pump & & $16 \%$ & $10 \%$ & $40 \%$ & $35,095,568$ & $1 \%$ & $0 \%$ \\
\hline & ENERGY STAR Rooftop HP v. 2.2 & & $5 \%$ & $10 \%$ & $40 \%$ & $12,283,800$ & $0 \%$ & $0 \%$ \\
\hline & Prospective Commercial AVCTHVAC & & $45 \%$ & $3 \%$ & $40 \%$ & $25,513,366$ & $0 \%$ & $0 \%$ \\
\hline & Prospective Commercial NVC HVAC & & $52 \%$ & $3 \%$ & $40 \%$ & $29,275,059$ & $1 \%$ & $0 \%$ \\
\hline & Add enthalpy wheels & & & & $40 \%$ & 0 & $0 \%$ & $0 \%$ \\
\hline
\end{tabular}

Figure 16. PREESAT commercial tab efficiency measures for HVAC end use

\begin{tabular}{|c|c|c|c|c|c|}
\hline $\begin{array}{c}\text { End-Use } \\
\text { Percentage } \\
\text { (Column 2) }\end{array}$ & $\begin{array}{c}\text { Percent Electricity } \\
\text { Savings from Baseline } \\
\text { (Column 3) }\end{array}$ & $\begin{array}{c}\text { Portfolio } \\
\text { Percentage } \\
\text { (Column 4) }\end{array}$ & $\begin{array}{l}\text { Level of } \\
\text { Adoption } \\
\text { (Column 5) }\end{array}$ & $\begin{array}{c}\text { Commercial } \\
\text { Sector } \\
\text { Electricity Use }\end{array}$ & $\begin{array}{c}\text { Electricity } \\
\text { Savings } \\
\text { (Column 6) }\end{array}$ \\
\hline $\begin{array}{l}54 \% \text { of } \\
\text { commercial } \\
\text { consumption } \\
\text { from HVAC }\end{array}$ & $\begin{array}{l}16 \% \text { electricity savings } \\
\text { from baseline for } \\
\text { upgrading to the best } \\
\text { commercial rooftop AC }\end{array}$ & $\begin{array}{l}25 \% \text { of HVAC } \\
\text { upgrades } \\
\text { take this } \\
\text { measure }\end{array}$ & $\begin{array}{c}40 \% \text { of } \\
\text { commercial } \\
\text { customers } \\
\text { upgrade HVAC }\end{array}$ & $\begin{array}{c}\text { 10,378,305,301 } \\
\text { kWh in } 2040 \\
\text { (baseline BAU } \\
\text { forecast) }\end{array}$ & $\begin{array}{c}87,544,540 \\
\text { kWh/yr. of } \\
\text { electricity } \\
\text { savings }\end{array}$ \\
\hline
\end{tabular}

Figure 17. Calculation of electricity savings in 2040 (compared to the baseline) that due to user-specified adoption levels for the Best Commercial Rooftop AC measure 


\subsection{Commercial Sector Analysis}

We analyzed energy efficiency measures for Puerto Rico's commercial sector using PREESAT in order to identify electricity and cost savings opportunities (Avilés et al. 2020). Because the commercial sector uses the most electricity, efficiency measures focused on the large end uses, such as HVAC and lighting, are highly impactful. For cooling, rooftop units and chillers could be upgraded to more efficient versions or different technologies such as heat pumps. For lighting, LED fixtures are the most efficient technology. More efficient refrigeration units, building envelope improvements such as increased insulation, and occupancy controls, as well as other sensors are also important. Our analysis would be enhanced by using local data from Puerto Rico rather than analogous data from the mainland United States, despite the similarities.

\section{The Industrial Sector Measures in PREESAT}

In 2018, the industrial sector's 565 customers used 2,128 GWh of electricity, making it the most energy-intensive sector ( $\mathrm{GWh} /$ customer) and accounting for $13 \%$ of total electricity use in Puerto Rico (IRP 2019). The main industries that comprise this sector are pharmaceuticals, biotechnology, medical devices, and food and beverage production. Based on expert interviews, electricity consumption profiles in Puerto Rico's industrial sector are comparable to that of industrial sectors in the mainland United States, where the primary end uses are machine drive motors, process use, and other direct uses, including heating and cooling (Figure 18); this is according to 2010 data from the U.S. Environmental Protection Agency. ${ }^{5}$

\footnotetext{
5 "Energy and Environment: Electricity Customers," U.S. Environmental Protection Agency, https://www.epa.gov/energy/electricity-customers, accessed June 8, 2021.
} 


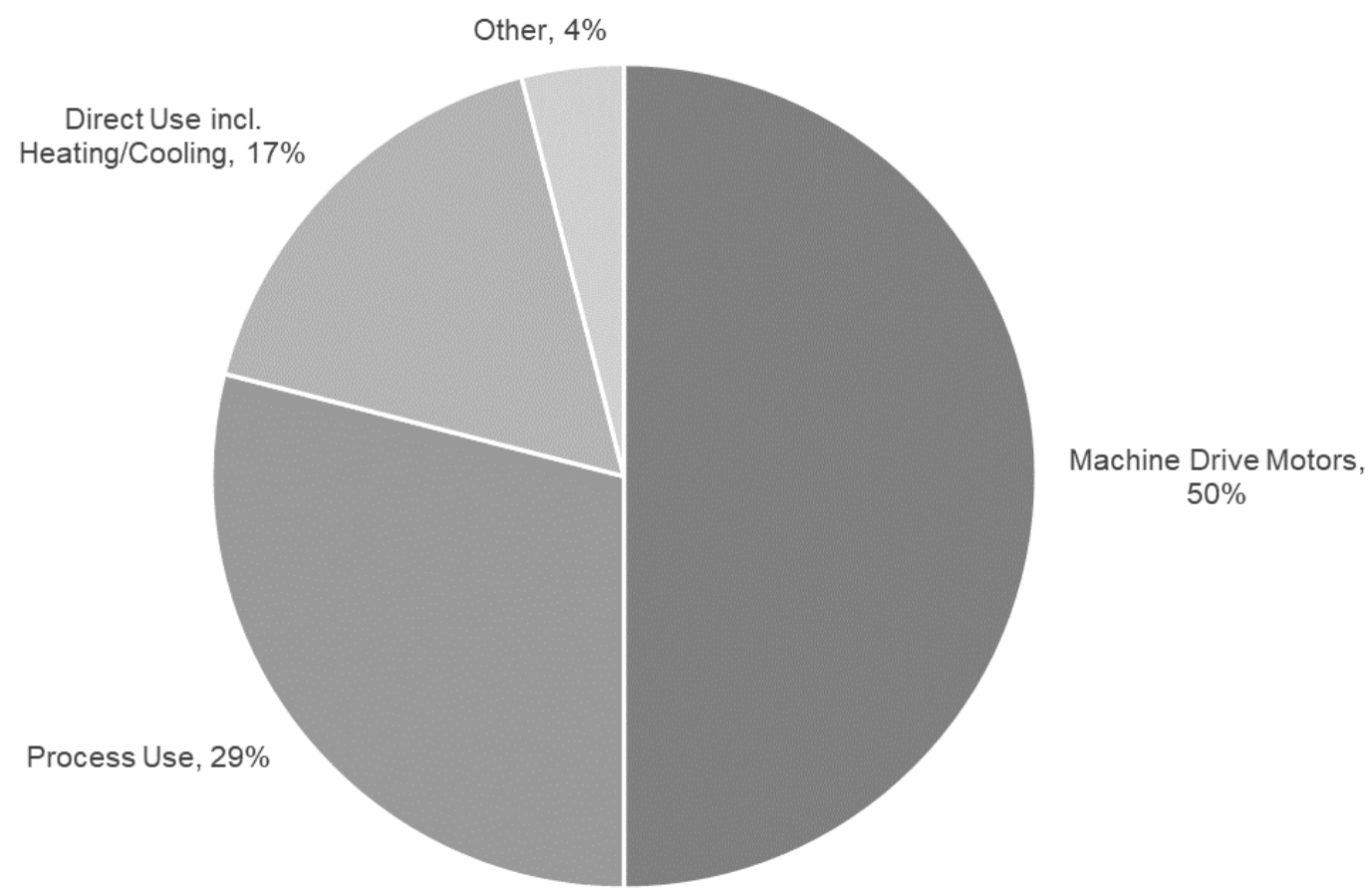

Figure 18. Industrial sector electricity end uses in the mainland United States

\subsection{Industrial Sector Data and Assumptions}

The DOE industrial assessment centers program conducts energy audits for industrial customers and provides estimates of energy and cost savings by selecting applicable measures from a comprehensive list of energy conservation measures. And the electricity savings estimates for industrial energy efficiency measures in PREESAT are mainly sourced from the Industrial Assessment Centers Database.

Between 2007 and 2020, the industrial assessment centers program at the University of Miami conducted 55 energy audits of Puerto Rican industrial customers representing a variety of industries, including pharmaceuticals, medical devices, dairy, food and beverage, apparel, healthcare, and biotechnology. According to those audits, these subsectors collectively accounted for around $16 \%$ of the entire industrial electricity consumption in Puerto Rico. PREESAT assumes this local data set is a representative sample of the entire industrial sector in Puerto Rico. PREESAT uses detailed data from the 20 largest audited industrial customers, which represented $12 \%$ of the industrial load in Puerto Rico; and the tool uses a weighted average of the percentage savings estimates for each applicable energy efficiency measure to estimate average electricity savings for each measure across the sector. Using the largest customers from the data set might introduce a slight bias toward industrial savings potential for larger customers. And this potential bias could actually lead to an underestimation of the industrial sector energy efficiency potential overall, as these larger customers are more likely than smaller customers to have the resources and backing to have already invested in energy efficiency upgrades, as was acknowledged in interviews conducted with local stakeholders.

PREESAT also calculates the percentage of industrial customers for whom each measure is both applicable and financially beneficial, as determined by the industrial assessment center audits. 
This is particularly relevant in the industrial sector because electricity consumption patterns are diverse and many customers have likely already undertaken some energy efficiency improvements. Based on expert input and review, some estimates were adjusted and additional measures were added. Overall, PREESAT considers 46 industrial energy efficiency measures, which are shown in Figure 19. 


\begin{tabular}{|c|}
\hline ANALYZE FLUE GAS FOR PROPER AIR/FUEL RATIO \\
\hline USE HEAT FROM BOILER BLOWDOWN TO PREHEAT BOILER FEED WATER \\
\hline USE WASTE HEAT FROM HOT FLUE GASES TO PREHEAT \\
\hline PAY UTILITY BILLS ON TIME \\
\hline CLOSELY MONITOR CHEMICAL ADDITIONS TO INCREASE BATH LIFE \\
\hline REPAIR OR REPLACE STEAM TRAPS \\
\hline OPTIMIZE PLANT POWER FACTOR \\
\hline ISOLATE HOT OR COLD EQUIPMENT \\
\hline USE OPTIMUM THICKNESS INSULATION \\
\hline REPLACE TREATED WATER WITH WELL / SURFACE WATER \\
\hline REDUCE EXCESSIVE BOILER BLOWDOWN \\
\hline CHANGE RATE SCHEDULES OR OTHER CHANGES IN UTILITY SERVICE \\
\hline USE A FOSSIL FUEL ENGINE TO COGENERATE ELECTRICITY OR MOTIVE POWER; AND UTILIZE HEAT \\
\hline USE PHOTOCELL CONTROLS \\
\hline AVOID INTRODUCING HOT, HUMID, OR DIRTY AIR INTO HVAC SYSTEM \\
\hline UTILIZE ENERGY-EFFICIENT BELTS AND OTHER IMPROVED MECHANISMS \\
\hline UTILIZE ENERGY-EFFICIENT BELTS AND OTHER IMPROVED MECHANISMS \\
\hline UTILIZE DAYLIGHT WHENEVER POSSIBLE IN LIEU OF ARTIFICIAL LIGHT \\
\hline RECOVER WASTE HEAT FROM EQUIPMENT \\
\hline REPLACE EXISTING HVAC UNIT WITH HIGH EFFICIENCY MODEL \\
\hline UPGRADE OBSOLETE EQUIPMENT \\
\hline USE SOLAR HEAT TO HEAT WATER \\
\hline MAINTAIN AIR FILTERS BY CLEANING OR REPLACEMENT \\
\hline USE MOST EFFICIENT TYPE OF ELECTRIC MOTORS \\
\hline RE-USE OR RECYCLE HOT OR COLD PROCESS EXHAUST AIR \\
\hline INSTALL OCCUPANCY SENSORS \\
\hline INSTALL PARTITIONS TO REDUCE SIZE OF CONDITIONED SPACE \\
\hline USE OPTIMUM SIZE AND CAPACITY EQUIPMENT \\
\hline INSTALL VINYL STRIP / HIGH SPEED / AIR CURTAIN DOORS \\
\hline UTILIZE A LESS EXPENSIVE COOLING METHOD \\
\hline INSULATE GLAZING, WALLS, CEILINGS, AND ROOFS*** \\
\hline CLOSE HOLES AND OPENINGS IN BUILDING SUCH AS BROKEN WINDOWS \\
\hline INSTALL / REPAIR INSULATION ON STEAM LINES \\
\hline ELIMINATE OR REDUCE COMPRESSED AIR USAGE \\
\hline USE OR REPLACE WITH ENERGY EFFICIENT SUBSTITUTES \\
\hline UTILIZE AN EVAPORATIVE AIR PRE-COOLER OR OTHER HEAT EXCHANGER IN AC SYSTEM \\
\hline INSTALL WASTE HEAT BOILER TO PRODUCE STEAM \\
\hline REPLACE EXISTING CHILLER WITH HIGH EFFICIENCY MODEL \\
\hline UTILIZE HIGHER EFFICIENCY LAMPS AND/OR BALLASTS \\
\hline ELIMINATE LEAKS IN INERT GAS AND COMPRESSED AIR LINES/ VALVES \\
\hline LOWER TEMPERATURE DURING THE WINTER SEASON AND VICE-VERSA \\
\hline USE ADJUSTABLE FREQUENCY DRIVE OR MULTIPLE SPEED MOTORS ON EXISTING SYSTEM \\
\hline TURN OFF EQUIPMENT WHEN NOT IN USE \\
\hline CLEAN OR COLOR ROOF TO REDUCE SOLAR LOAD \\
\hline IMPLEMENT ENERGY MONITORING SYSTEM ${ }^{* * * *}$ \\
\hline HIRE (IN HOUSE OR CONTRACT) ENERGY PROGRAM MANAGEMENT**** \\
\hline
\end{tabular}

Figure 19. Industrial efficiency measures in PREESAT 


\subsection{PREESAT Industrial Tab: User Guidance}

The PREESAT industrial tab allows users to choose a value for the Set Overall Adoption Percentage for Efficiency Measures input and view the resulting sector-specific percentage reduction in electricity consumption in 2040 compared to the baseline (Figure 20, page 25). The efficiency measures described in this section are listed in Column 3. The main user input represents the percentage of industrial customers that will adopt a measure that is viable for them - not the percentage of all industrial customers who will adopt that measure. This input sets the values in Column 3. Not all measures are feasible for every customer, as some measures may have already been implemented by certain customers and other measures may not be applicable to certain customers. The adoption percentage in Column 3 is multiplied by the estimated electricity savings, shown in Column 2, and the estimated percentage of customers for whom this measure is viable, shown in Column 4 . The calculation yields the percentage reduction in industrial electricity consumption in 2040 compared to the baseline, shown in Column 5, for each efficiency measure. The values in Column 5 are aggregated to determine the result in the Total Percentage Reduction in Industrial Electricity Consumption in 2040 Compared to Baseline box at the top of the tab. This value is fed into the PREESAT dashboard summary calculations.

An example of the values for Columns 1-5, for the Use Adjustable Frequency Drive or Multiple Speed Motors on Existing System measure is shown in Figure 21 (page 26). As indicated in Column 2, this intervention results in a $2.79 \%$ reduction in electricity consumption compared to the baseline. Users indicate that $50 \%$ of industrial customers will adopt an efficiency measure that is viable for them, which populates the value in Column 3. Column 4 indicates this measure is only viable for $50 \%$ of all industrial customers. Column 5 calculates that the Use Adjustable Frequency Drive or Multiple Speed Motors in Existing System measure, which is based on the values in Columns $2-4$, will result in a $0.70 \%$ reduction in overall industrial electricity consumption in 2040 compared to the baseline (Figure 22, page 26). 
Industrial Energy Efficiency Measures

\begin{tabular}{|c|c|c|c|c|c|c|c|}
\hline \multicolumn{8}{|c|}{ Industrial Energy Efficiency Measures } \\
\hline Legend: & Calculated in Spreadsheet & User Input & \multicolumn{2}{|c|}{ Links to Other Spreadsheet Data } & Hard Entries & Data Under Investigation & \\
\hline \multicolumn{2}{|c|}{$\begin{array}{l}\text { Total Percent Reduction in Industrial Electricity Consumption in } 2040 \\
\text { Compared to Baseline: }\end{array}$} & \multirow{3}{*}{\multicolumn{2}{|c|}{ Return to Dashboard }} & \multicolumn{4}{|c|}{ Set Overall Adoption Percentage for Efficiency Measures: } \\
\hline \multicolumn{2}{|c|}{$16 \%$} & & & \multicolumn{4}{|c|}{$50 \%$} \\
\hline \multicolumn{2}{|l|}{ Column 1} & & & & Column 3 & Column 4 & Column 5 \\
\hline \multicolumn{2}{|c|}{ IAC Industrial EE Measure } & \%Electricity Sa & npared to Baseline & $\begin{array}{l}\text { \% of Inc } \\
\text { End-Use }\end{array}$ & $\begin{array}{l}\text { trial Customers Adopting } \\
\text { iciency Measures by } 2040^{*}\end{array}$ & $\begin{array}{l}\text { \% of Industrial Customers for } \\
\text { Whom Measure is Viable** }\end{array}$ & $\begin{array}{l}\text { \% Reduction in Industrial Electricity } \\
\text { Consumption in } 2040 \text { Compared to Baseline }\end{array}$ \\
\hline \multicolumn{2}{|c|}{ ANALYZE FLUE GAS FOR PROPER AIR/FUEL RATIO } & & & & $50 \%$ & $0 \%$ & $0.00 \%$ \\
\hline \multicolumn{2}{|c|}{ USE HEAT FROM BOILER BLOWDOWN TO PREHEAT BOILER FEED WATER } & & & & $50 \%$ & $0 \%$ & $0.00 \%$ \\
\hline \multicolumn{2}{|c|}{ USE WASTE HEAT FROM HOT FLUE GASES TO PREHEAT } & & & & $50 \%$ & $0 \%$ & $0.00 \%$ \\
\hline \multicolumn{2}{|l|}{ PAY UTILITY BILLS ON TIME } & & & & $50 \%$ & $0 \%$ & $0.00 \%$ \\
\hline \multicolumn{2}{|c|}{ CLOSELY MONITOR CHEMICAL ADDITIONS TO INCREASE BATH LIFE } & & & & $50 \%$ & $0 \%$ & $0.00 \%$ \\
\hline \multicolumn{2}{|c|}{ REPAIR OR REPLACE STEAM TRAPS } & & & & $50 \%$ & $0 \%$ & $0.00 \%$ \\
\hline \multicolumn{2}{|l|}{ OPTIMIZE PLANT POWER FACTOR } & & & & $50 \%$ & $0 \%$ & $0.00 \%$ \\
\hline \multicolumn{2}{|l|}{ ISOLATE HOT OR COLD EQUIPMENT } & & & & $50 \%$ & $0 \%$ & $0.00 \%$ \\
\hline \multicolumn{2}{|l|}{ USE OPTIMUM THICKNESS INSULATION } & & & & $50 \%$ & $0 \%$ & $0.00 \%$ \\
\hline \multicolumn{2}{|l|}{ REPLACE TREATED WATER WITH WELL / SURFACE WATER } & & & & $50 \%$ & $0 \%$ & $0.00 \%$ \\
\hline \multicolumn{2}{|c|}{ REDUCE EXCESSIVE BOILER BLOWDOWN } & & & & $50 \%$ & $0 \%$ & $0.00 \%$ \\
\hline \multicolumn{2}{|c|}{ CHANGE RATE SCHEDULES OR OTHER CHANGES IN UTILLTY SERVICE } & & & & $0 \%$ & $0 \%$ & $0.00 \%$ \\
\hline \multicolumn{2}{|c|}{ USE A FOSSIL FUEL ENGINE TO COGENERATE ELECTRICITY OR MOTIVE POWER; AND UTILIZE HEAT } & & & & $50 \%$ & $15 \%$ & $3.75 \%$ \\
\hline \multicolumn{2}{|c|}{ USE PHOTOCELL CONTROLS } & & & & $50 \%$ & $10 \%$ & $0.00 \%$ \\
\hline \multicolumn{2}{|c|}{ AVOID INTRODUCING HOT, HUMID, OR DIRTY AIR INTO HVAC SYSTEM } & & & & $50 \%$ & $5 \%$ & $0.01 \%$ \\
\hline \multicolumn{2}{|c|}{ UTILIZE ENERGY-EFFICIENT BELTS AND OTHER IMPROVED MECHANISMS } & & & & $50 \%$ & $15 \%$ & $0.01 \%$ \\
\hline \multicolumn{2}{|c|}{ UTILIZE ENERGY-EFFICIENT BELTS AND OTHER IMPROVED MECHANISMS } & & & & $50 \%$ & $15 \%$ & $0.01 \%$ \\
\hline UTILIZE DAYLIGHT WHENEVER POSSIBLE IN LIEU OF AR & LIGHT & & & & $50 \%$ & $10 \%$ & $0.01 \%$ \\
\hline RECOVER WASTE HEAT FROM EQUIPMENT & & & & & $50 \%$ & $5 \%$ & $0.01 \%$ \\
\hline REPLACE EXISTING HVAC UNIT WITH HIGH EFFICIENCY & & & & & $50 \%$ & $5 \%$ & $0.02 \%$ \\
\hline UPGRADE OBSOLETE EQUIPMENT & & & & & $50 \%$ & $5 \%$ & $0.02 \%$ \\
\hline USE SOLAR HEAT TO HEAT WATER & & & & & $50 \%$ & $5 \%$ & $0.02 \%$ \\
\hline MAINTAIN AIR FILTERS BY CLEANING OR REPLACEMEN & & & & & $50 \%$ & $15 \%$ & $0.02 \%$ \\
\hline USE MOST EFFICIENT TYPE OF ELECTRIC MOTORS & & & & & $50 \%$ & $5 \%$ & $0.04 \%$ \\
\hline RE-USE OR RECYCLE HOT OR COLD PROCESS EXHAUST & & & & & $50 \%$ & $5 \%$ & $0.04 \%$ \\
\hline INSTALL OCCUPANCY SENSORS & & & & & $50 \%$ & $40 \%$ & $0.04 \%$ \\
\hline INSTALL PARTITIONS TO REDUCE SIZE OF CONDITIONE & & & & & $50 \%$ & $15 \%$ & $0.06 \%$ \\
\hline USE OPTIMUM SIZE AND CAPACITY EQUIPMENT & & & & & $50 \%$ & $35 \%$ & $0.07 \%$ \\
\hline INSTALL VINYL STRIP / HIGH SPEED / AIR CURTAIN DOC & & & & & $50 \%$ & $25 \%$ & $0.09 \%$ \\
\hline UTILIZE A LESS EXPENSIVE COOLING METHOD & & & & & $50 \%$ & $10 \%$ & $0.12 \%$ \\
\hline INSULATE GLAZING, WALLS, CEILINGS, AND ROOFS*** & & & & & $50 \%$ & $5 \%$ & $0.13 \%$ \\
\hline CLOSE HOLES AND OPENINGS IN BUILDING SUCH AS B & VINDOWS & & & & $50 \%$ & $5 \%$ & $0.14 \%$ \\
\hline
\end{tabular}

Figure 20. PREESAT industrial tab 


\begin{tabular}{|c|c|c|c|c|}
\hline \multirow{2}{*}{$\begin{array}{c}\text { Total Percent Reduction in Industrial Electricity Consumption in } 2040 \\
\text { Compared to Baseline: } \\
16 \% \\
\end{array}$} & \multirow{2}{*}{ Return to Dashboard } & \multicolumn{3}{|c|}{ Set Overall Adoption Percentage for Efficiency Measures: } \\
\hline & & \multicolumn{3}{|c|}{$50 \%$} \\
\hline $\begin{array}{r}\text { Column } 1 \\
\end{array}$ & Column 2 & Column 3 & Column 4 & Column 5 \\
\hline IAC Industrial EE Measure & \% Electricity Savings Compared to Baseline & $\begin{array}{l}\text { \% of Industrial Customers Adopting } \\
\text { End-Use Efficiency Measures by } 2040^{*}\end{array}$ & $\begin{array}{l}\% \text { of Industrial Customers for } \\
\text { Whom Measure is Viable }\end{array}$ & $\begin{array}{l}\text { \% Reduction in Industrial Electricity } \\
\text { Consumption in } 2040 \text { Compared to Baseline }\end{array}$ \\
\hline USE ADJUSTABLE FREQUENCY DRIVE OR MULTIPLE SPEED MOTORS ON EXISTING SYSTEM & $2.79 \%$ & $50 \%$ & $50 \%$ & $0.70 \%$ \\
\hline
\end{tabular}

Figure 21. PREESAT industrial tab efficiency measures of Use Adjustable Frequency Drive or Multiple Speed Motors on Existing System

\begin{tabular}{|c|c|c|c|c|c|}
\hline $\begin{array}{c}\text { Percent Electricity } \\
\text { Savings from Baseline } \\
\text { (Column 2) }\end{array}$ & $x$ & $\begin{array}{l}\text { Level of } \\
\text { Adoption } \\
\text { (Column 3) }\end{array}$ & $x$ & $\begin{array}{c}\text { Percent } \\
\text { Viable } \\
\text { (Column 4) }\end{array}$ & $\begin{array}{c}\text { Total Industrial } \\
\text { Percent Savings from } \\
\text { Baseline (Column 5) }\end{array}$ \\
\hline $\begin{array}{l}2.79 \% \text { electricity savings } \\
\text { from baseline for using } \\
\text { adjustable frequency drive } \\
\text { or multiple speed motors }\end{array}$ & $x$ & $\begin{array}{l}50 \% \text { of } \\
\text { customers will } \\
\text { adopt viable } \\
\text { measure }\end{array}$ & $x$ & $\begin{array}{l}\text { Measure is } \\
\text { viable for } \\
50 \% \text { of } \\
\text { customers }\end{array}$ & $\begin{array}{l}0.70 \% \text { reduction in total } \\
\text { industrial electricity } \\
\text { consumption in } 2040 \\
\text { compared to baseline }\end{array}$ \\
\hline
\end{tabular}

Figure 22. Example calculation of electricity savings in 2040 (compared to the baseline) that are due to user-specified adoption levels for the Use Adjustable Frequency Drive or Multiple Speed Motors in Existing System measure 


\subsection{Industrial Sector Analysis}

We analyzed energy efficiency measures for Puerto Rico's industrial sector using PREESAT in order to identify electricity and cost savings opportunities (Avilés et al. 2020). Although the industrial assessment center audits are fairly recent, there are no data about how many industrial customers have already implemented certain efficiency measures. This is especially important, as many of the customers are large multinational corporations with their own internal energy efficiency goals. Furthermore, the needs and uses of electricity vary greatly even though there are concentrations of similar customers in Puerto Rico, such as the pharmaceuticals and biotechnology industries. Because the industrial sector is the most energy-intensive, efficiency improvements, even if individualized to a particular customer, can still have a significant impact. Our analysis estimates that potential savings could be $562 \mathrm{GWh} /$ year, resulting in a $25 \%$ reduction of industrial electricity consumption and a 3\% reduction of total electricity consumption in Puerto Rico.

\section{Integrated Scenarios in PREESAT and the P.L. 17- 2019 Target}

An advantage of PREESAT is that it enables exploration of various pathways and scenarios to reach specific energy efficiency goals. For instance, policymakers can use the tool to help guide decisions about funding residential, commercial, or industrial programs and which specific end uses warrant the most focus. However, it is important to note that it is very difficult to forecast the future and project which technologies and programs will exist that could enable even greater energy efficiency savings in the coming decades. PREESAT only considers current commercially available technology solutions; given the horizon of the tool is more than 20 years, new energy efficiency options are likely to become commercially available and be implemented. Nevertheless, exploring several integrated scenarios for reducing electricity consumption is still useful. So, although the real value of the tool lies in user customization, in this section, we present energy efficiency measure adoption scenarios that can attain a $30 \%$ reduction in electricity consumption from a BAU baseline by 2040 via efficiency measures.

Although PREB specified in April 2021 that the baseline for P.L. 17-2019 is FY19 electricity sales, we developed these integrated scenarios before PREB's clarification. Therefore, our integrated scenarios use the PREESAT Medium Demand BAU forecast as the baseline, as described in Section 2.3. The results presented here use the default distributions of specific measures within each end use (e.g., $75 \%$ of residential lighting upgrades will replace incandescent bulbs with LEDs and 25\% will upgrade compact fluorescent lightbulbs to LEDs). Because exact data on distribution of devices in Puerto Rico are scarce and the likelihood of any energy efficiency upgrade will change over time, users can modify these distributions to be more representative of current trends.

Finally, the scenarios we present in this section are meant to illustrate how users might use PREESAT - not to suggest future pathways or display replicable results. Street lighting remains at the same efficiency assumptions described in Section 3.2 throughout all these scenarios. 


\subsection{Scenario A: Uniform Percentage Adoption}

Scenario A explores uniform adoption of all the potential energy efficiency measures presented in PREESAT - every measure across every sector has the same adoption percentage over the 20year analysis period. This universal adoption percentage was adjusted incrementally to reach various electricity savings goals (Figure 23). For example, a uniform adoption percentage of $20 \%$ leads to a $12 \%$ reduction in electricity consumption compared to the Medium Demand BAU forecast in 2040.

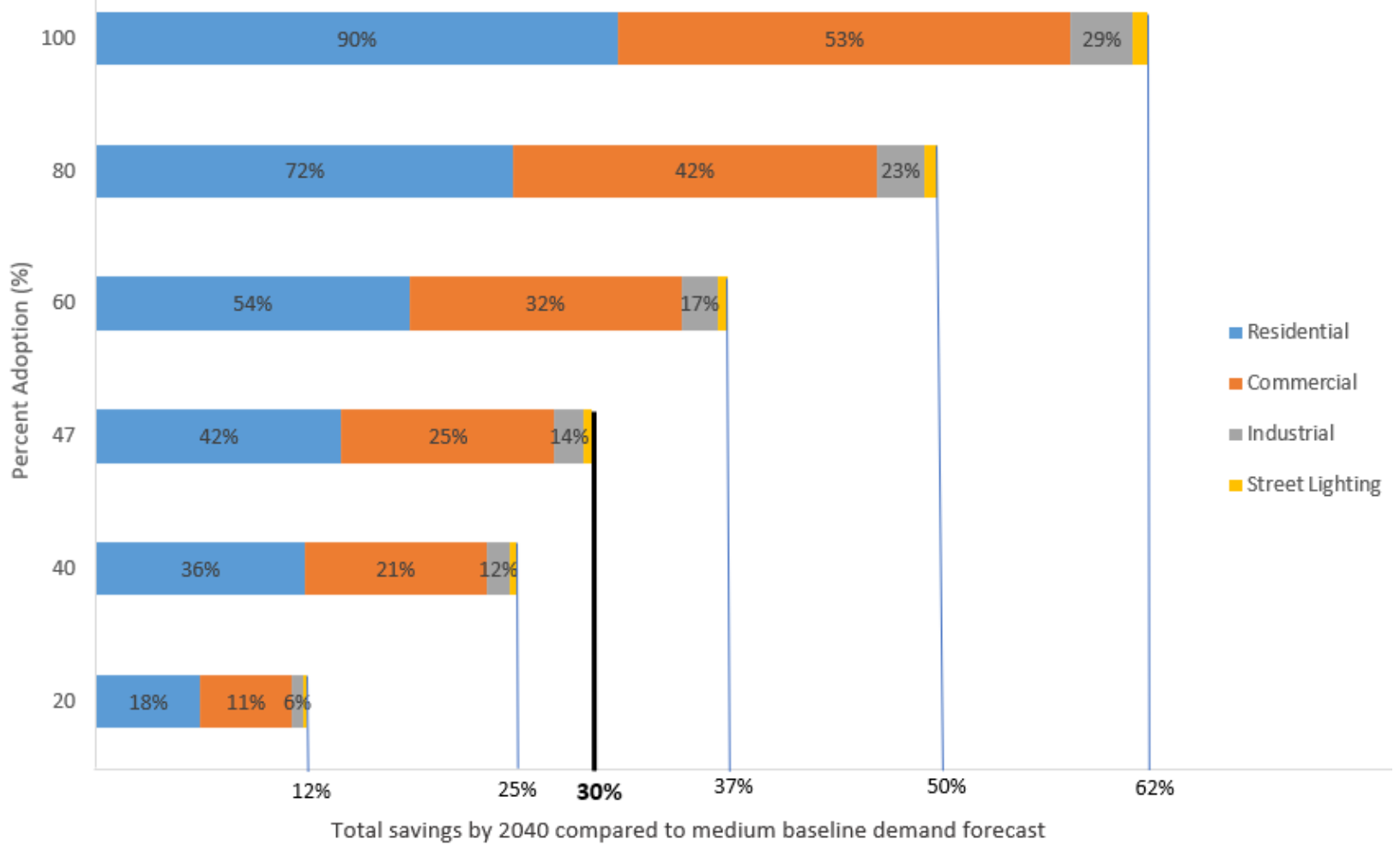

Figure 23. Total energy savings by 2040 as universal percentage adoption changes

The black percentages in the bars represent the reduction from that sector's baseline electricity use.

Though $47 \%$ may initially seem high as the universal adoption percentage needed to reach the $30 \%$ target, it is realistic over a 20 -year time-frame. Many appliance upgrades will occur naturally as customers retire old equipment and purchase newer, more energy efficient replacements. Furthermore, future appliances and technologies are likely to offer even greater reductions in energy use than currently available options.

\subsection{Scenario B: Residential Focus}

As seen in Scenario A, at any specific universal adoption percentage, the residential sector reduces its energy demand the most. For example, a $42 \%$ reduction in residential energy use results from the $47 \%$ universal adoption scenario (Figure 23). The residential sector also has by far the most utility customers. So, a programmatic focus on the residential sector could have a significant impact. Scenario B attains a 30\% reduction in energy use by 2040 with a residential adoption percentage of 55\% and a commercial and industrial adoption percentage of $25 \%$ (Figure 24). 


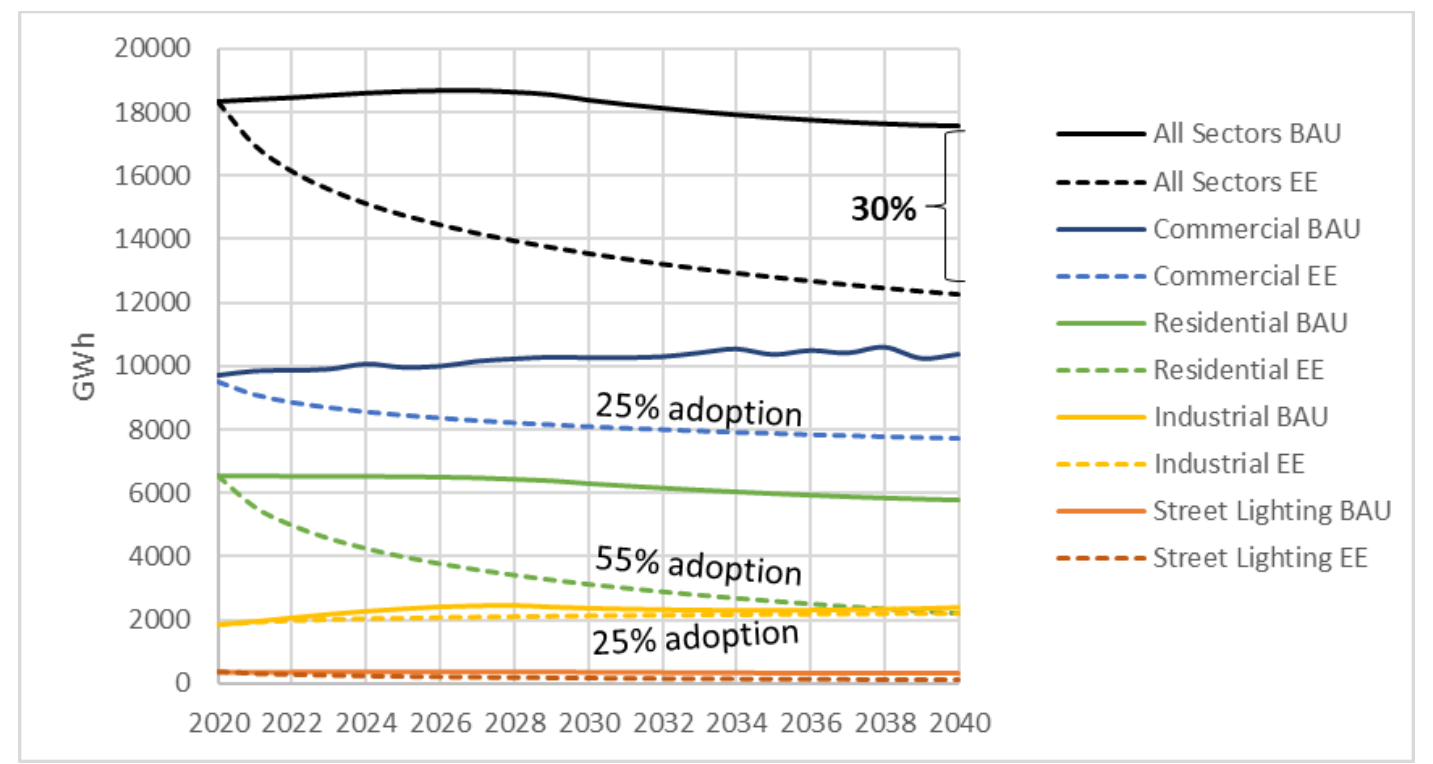

Figure 24. Residential Focus scenario results

A $30 \%$ reduction in energy use from the baseline BAU scenario occurs with a residential adoption rate of $55 \%$ and a commercial and industrial adoption rate of $25 \%$.

\subsection{Scenario C: Commercial Focus}

The commercial sector consumes the most electricity in Puerto Rico and has fewer customers than the residential sector. So, a commercial sector program is likely easier to implement than a residential-focused program and could result in more savings per dollar spent. Also, a lack of data on the commercial sector's energy use increases uncertainty of this scenario's results. If commercial buildings in Puerto Rico are generally less efficient than those in Miami that were used for the basis of this analysis, the opportunity for energy savings in this under-analyzed sector is even greater than is estimated in PREESAT. Scenario C attains a $30 \%$ reduction in energy use by 2040 , with a commercial adoption percentage of $60 \%$ and a residential and industrial adoption percentage of $25 \%$ (Figure 25 ). 


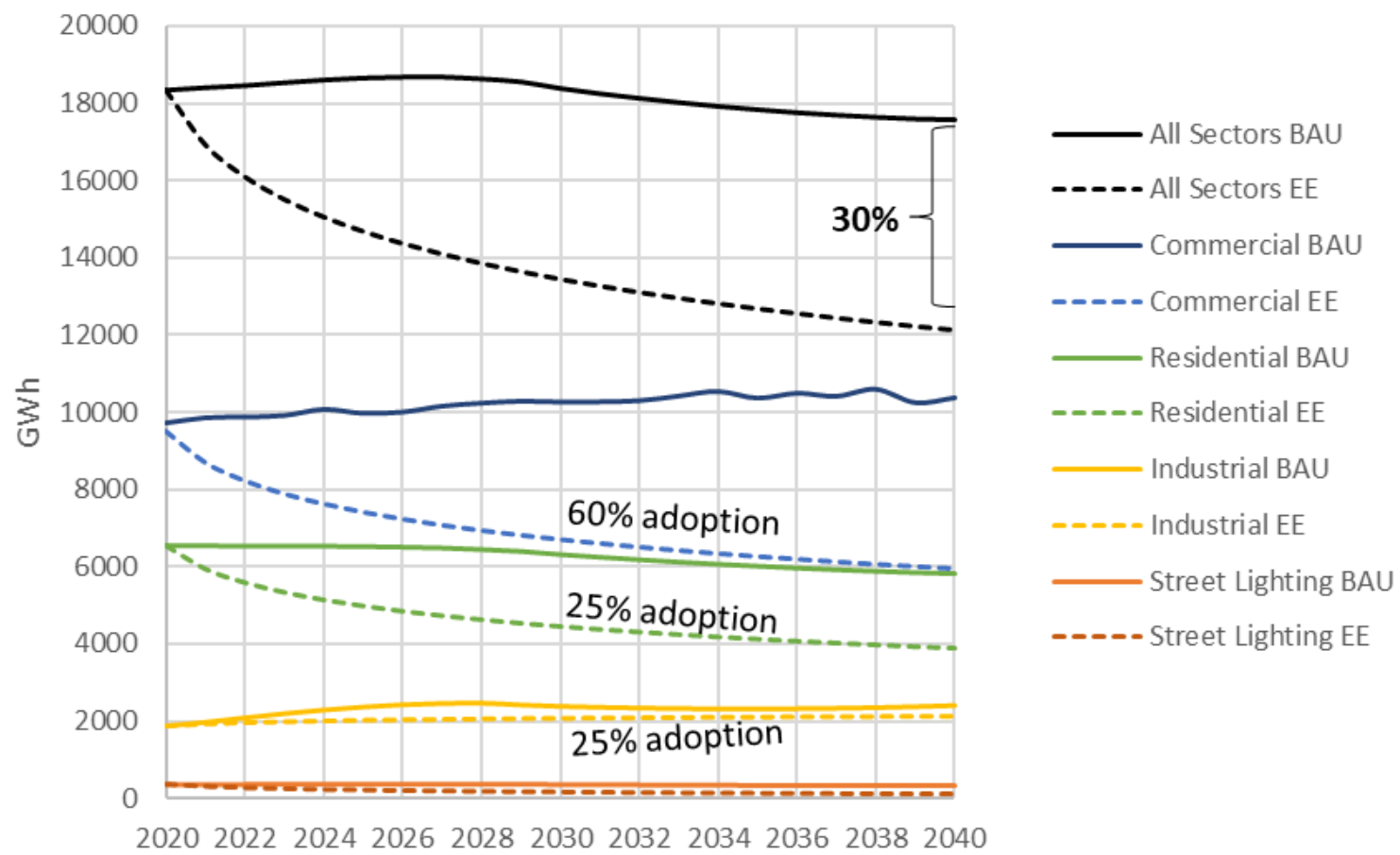

Figure 25. Commercial Focus scenario results

A $30 \%$ reduction in energy use from the baseline BAU scenario occurs with a commercial adoption rate of $60 \%$ and a residential and industrial adoption rate of $25 \%$.

\subsection{Scenario E: Cooling and Lighting Focus Across All Sectors}

A focus on cooling and lighting loads might yield the most effective programmatic plan. And this is the approach that the PREPA IRP takes in its energy efficiency forecast analysis-though for the residential and commercial sectors only. PREESAT allows for a focus on specific cooling and lighting upgrades as well, so this scenario will push the cooling and lighting options that offer the highest savings. For the residential sector, this means promoting mini-split systems and SEER 12 window units (50\% end-use portfolio adoption for each) and upgrades to LEDs ( $75 \%$ from incandescent and $25 \%$ from compact fluorescent lightbulbs). For the commercial sector, the specific cooling and lighting measures will focus investment on ASHRAE 90.1-2016 or better commercial chillers, the best rooftop AC units, and the best rooftop heat pumps (30\% end-use portfolio adoption for each), as well as the prospective best commercial HVAC (10\% end-use portfolio adoption percentage) and upgrading to ENERGYSTAR Commercial LED lighting ( $75 \%$ end-use portfolio adoption). For the industrial sector, various cooling and lighting measures are considered in this scenario. Across the sectors, a cooling and lighting adoption percentage of $80 \%$ can achieve $30 \%$ energy reduction by 2040 . For this scenario, all other enduse measures are set to $25 \%$ adoption with default assumptions maintained. The results are shown in Figure 26. 


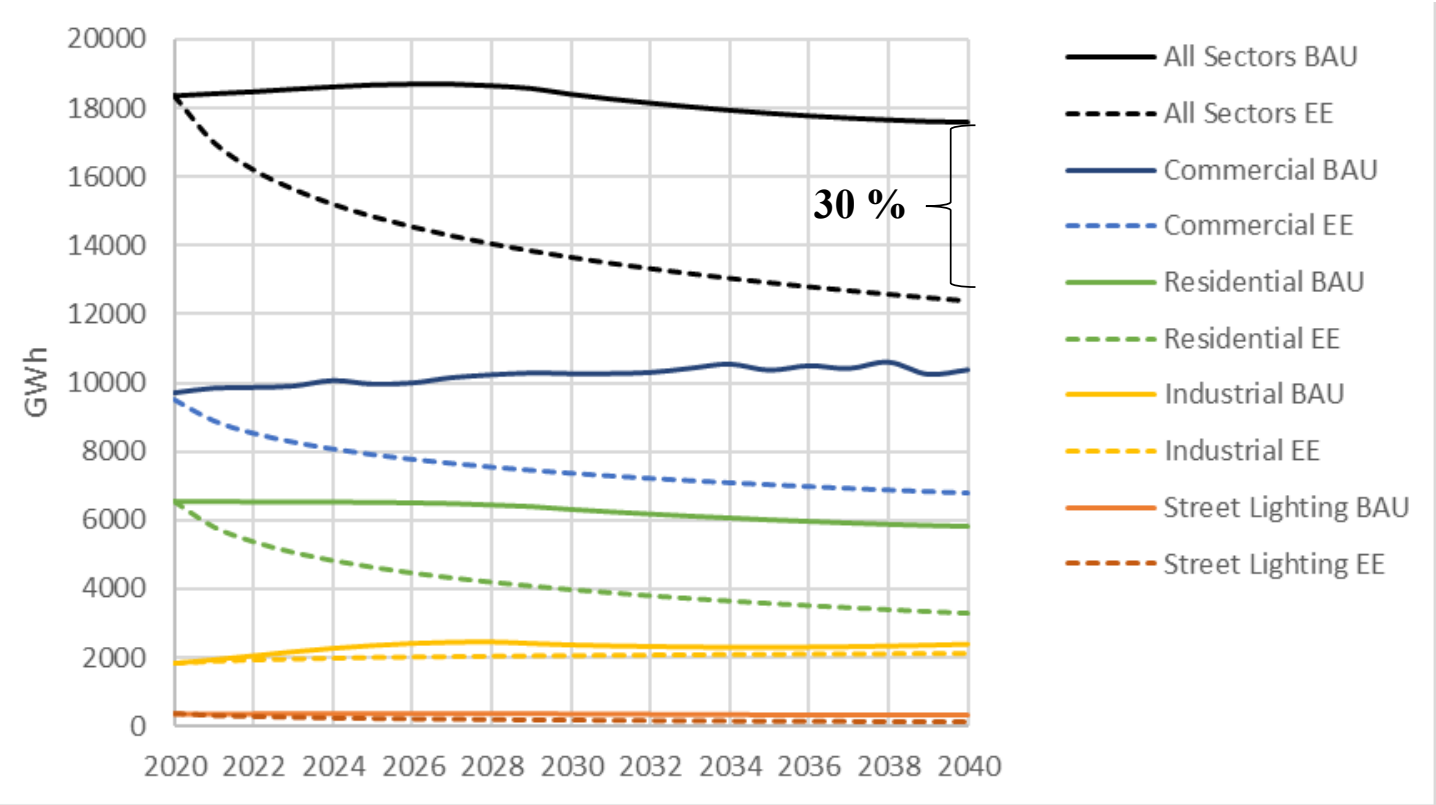

Figure 26. Cooling and Lighting Focus scenario results

\section{Conclusion}

PREESAT can help policymakers and analysts plan energy efficiency scenarios and estimate the resulting electricity consumption reductions. As a spreadsheet-based tool, all aspects of PREESAT can be modified as more data or revised demand forecasts become available. It relies on data from outside Puerto Rico to create many of its energy reduction estimates, but local data are always preferable. Future work could include incorporating more local data (particularly in the commercial sector), adding the costs of efficiency measures, and analyzing the impact of specific energy efficiency programs within the tool.

\section{References}

Avilés, Luis A., Elizabeth Arnold, Ricardo Castillo, James Elsworth, Monisha Shah. 2020. "Puerto Rico: Emerging Opportunities for Energy Efficiency and Equitable Clean Energy Development." ACEEE Summer Study on Energy Efficiency in Buildings.

Siemens (Siemens Industry, Inc.). 2019. Puerto Rico Integrated Resource Plan 2018-2019: Draft for the Review of the Puerto Rico Energy Bureau. Prepared for Puerto Rico Electric Power Authority. Rev. [2]. https://aeepr.com/espr/QuienesSomos/Ley57/Plan\%20Integrado\%20de\%20Recursos/IRP2019\%20\%20Ex\%201.00\%20-\%20Main\%20Report\%20\%20REV2\%2006072019.pdf 